\title{
Gas-Wetting Alteration by Fluorochemicals and Its Application for Enhancing Gas Recovery in Gas-Condensate Reservoirs: A Review
}

\author{
Jiafeng Jin ${ }^{1,2}{ }^{1}$, Jinsheng Sun ${ }^{1,2,3, *}$, Kesheng Rong ${ }^{4}$, Kaihe Lv ${ }^{1}$, Tuan A. H. Nguyen ${ }^{5}{ }^{\circledR}$, \\ Ren Wang ${ }^{1,2,3}$, Xianbin Huang ${ }^{1}$, Yingrui Bai ${ }^{1}$, Jingping Liu ${ }^{1}$ and Jintang Wang ${ }^{1}$ \\ 1 School of Petroleum Engineering, China University of Petroleum, Qingdao 266580, China; \\ Jjf5211314@126.com (J.J.); 1kh54321@126.com (K.L.); wangrdr@cnpc.com.cn (R.W.); \\ 20170092@upc.edu.cn (X.H.); smart-byron@163.com (Y.B.); liujingping20@126.com (J.L.); \\ wangjintang163@126.com (J.W.) \\ 2 Key Laboratory of Unconventional Oil \& Gas Development, China University of Petroleum, \\ Ministry of Education, Qingdao 266580, China \\ 3 CNPC Engineering Technology R \& D Company Limited, Beijing 102206, China \\ 4 Engineering Technology Research Institute, Xinjiang Oilfield Company, CNPC, Karamay 841000, China; \\ Rksheng@petrochina.com.cn \\ 5 Sustainable Minerals Institute, Environment Centres (CMLR), University of Queensland, \\ Brisbane, QLD 4072, Australia; tuan.a.h.nguyen@uq.edu.au \\ * Correspondence: sunjsdri@cnpc.com.cn; Tel.: +86-0532-8698-1690
}

Received: 3 August 2020; Accepted: 31 August 2020; Published: 4 September 2020

\begin{abstract}
Gas-wetting alteration is a versatile and effective approach for alleviating liquid-blockage that occurs when the wellbore pressure of a gas-condensate reservoir drops below the dew point. Fluorochemicals are of growing interest in gas-wetting alteration because of their high density of fluorine groups and thermal stability, which can change the reservoir wettability into more favorable conditions for liquids. This review aims to integrate the overlapping research between the current knowledge in organic chemistry and enhanced oil and gas recovery. The difference between wettability alteration and gas-wetting alteration is illustrated, and the methods used to evaluate gas-wetting are summarized. Recent advances in the applications of fluorochemicals for gas-wetting alteration are highlighted. The mechanisms of self-assembling adsorption layers formed by fluorochemicals with different surface morphologies are also reviewed. The factors that affect the gas-wetting performance of fluorochemicals are summarized. Meanwhile, the impacts of gas-wetting alteration on the migration of fluids in the pore throat are elaborated. Furthermore, the Wenzel and Cassie-Baxter theories are often used to describe the wettability model, but they are limited in reflecting the wetting regime of the gas-wetting surface; therefore, a wettability model for gas-wetting is discussed. Considering the promising prospects of gas-wetting alteration, this study is expected to provide insights into the relevance of gas-wetting, surface morphology and fluorochemicals, further exploring the mechanism of flow efficiency improvement of fluids in unconventional oil and gas reservoirs.
\end{abstract}

Keywords: gas-wetting alteration; liquid-blocking effect; fluorochemical; morphology; flow behavior

\section{Introduction}

Over 172,700 billion cubic $\mathrm{m}$ of proven natural gas reserves worldwide can be found in gas-condensate reservoirs [1-3]. Major gas-condensate reservoirs around the world, such as the Arun gas field (Indonesia), Urengoy gas field (Russia), South Pars gas field (Iran), North Field (Qatar), Cupiagua oilfield (Colombia), Karachaganak oilfield (Kazakhstan), and Tarim oilfield (China), 
occupy important positions in the global energy supply [4]. Gas in low-permeability condensate reservoirs is mainly recovered by the elastic energy accumulated in rocks and fluids. Primary gas deliverability in gas-condensate reservoirs is promising when the gas channels in porous media are flowable. However, the gas phase tends to condense into a "liquid-ring" or "liquid-bank" region around the gas well once the wellbore pressure drops below the upper dew pressure (point 2 in Figure 1), leading to a sharp decline in gas productivity, known as liquid-blocking effect. Basically, all gas-condensate reservoirs experience the dilemma of severe liquid-blocking effect after long periods of isothermal depletion [5-7], and increasing the gas recovery from mature gas reservoirs has become a major concern [8].

The poor mobility of fluids in liquid-wetting porous media is recognized as one of the major causes of liquid blockage [9]. The migration and allocation of fluids in the pore throat are governed by reservoir wettability; the rock spontaneously imbibes and retains liquid phase due to capillary force, increasing the liquid saturation and decreasing gas permeability [10]. There are multiple approaches for mitigating the impact of the liquid-blocking effect, including the chemical-injection method, the pressure-maintenance method, the horizontal wells strategy, hydraulic fracturing, and the combination of two or more of these methods [7], among which gas-wetting alteration achieved by chemical injection has been arousing wide attention because of its easy operation and permanent effectiveness.

This study elaborates gas-wetting alteration and the mechanism by which it enhances gas recovery, along with a summary of methods for evaluating gas-wetting, the various fluorochemicals used to achieve gas-wetting, and influential factors; the difference between gas-wetting alteration and wettability alteration is explained, and the relationship between surface morphology and gas-wetting is illustrated. Subsequently, the effect of gas-wetting on the flow behaviors of fluids in porous media is summarized, providing a better insight into the behaviors of trapped liquids in gas-condensate reservoirs.

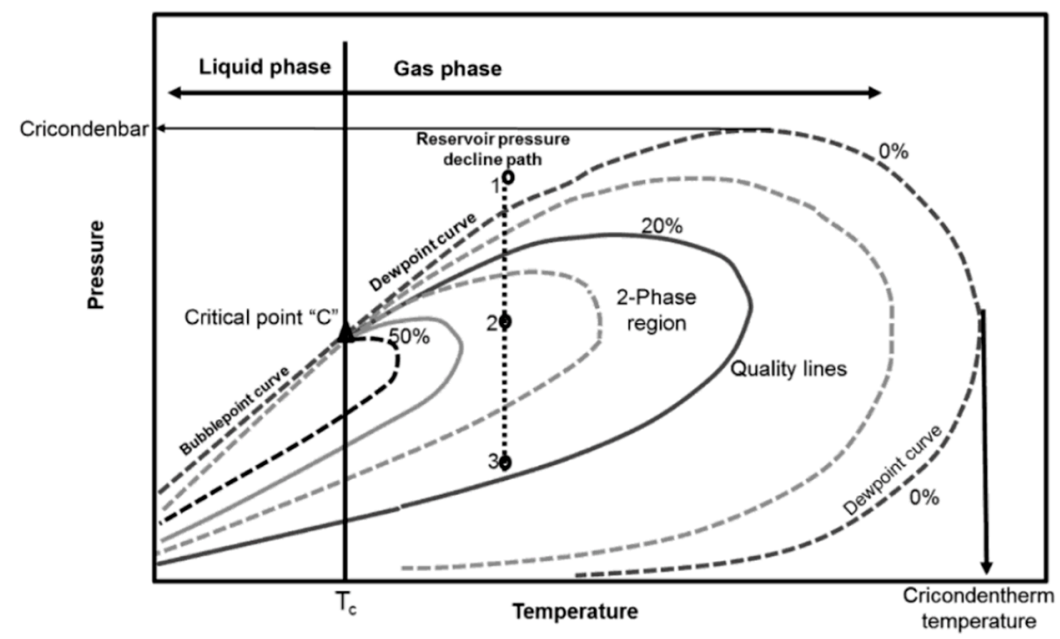

Figure 1. Typical temperature-pressure diagram for a multiphase system. Reproduced with persimission from [11], Copyright (C) 2010 Elsevier.

\section{Gas-Wetting Alteration and Its Effect on EOR}

\subsection{Gas-Wetting Alteration}

In 2000, the gas-wetting alteration technique was first proposed to alleviate the impact of liquid-blockage in gas-condensate reservoirs by altering reservoir wettability [12], which has been proved to be one of the most effective methods for improving the flow efficiency of fluid in the liquid-blocked region. Apart from condensate, another factor that contributes to liquid-blockage and loss of gas productivity is the presence of retained water, including the injected water and the water derived from the water-bearing formation [13]. It is difficult for the retained liquid in the pore throat 
to flow due to the low permeability and capillary pressure, and the combined effect of condensate and water in the wellbore region exacerbates the decrease in gas deliverability [6]; hence, the key to mitigating the liquid-blocking effect is to enhance the migration efficiency of both water and oil.

The principle of gas-wetting alteration is to change the rock wettability from liquid-wetting to gas-wetting by fluorochemicals; if the liquid saturation in the gas-wetting region is obviously less than that in the untreated region, then gas deliverability can be enhanced after gas-wetting alteration, as shown in Figure 2. It is worth noting that gas relative permeability might be more sensitive to the flow rate of fluids than liquid relative permeability, Li et al. [14] found that gas relative permeability increased as the flow rate increased after gas-wetting alteration, and a sharp decrease in gas relative permeability could be observed when the liquid saturation reached the critical condensate saturation; hence, it is reasonable to conclude that gas relative permeability increases due to the increase in the liquid mobility induced by gas-wetting alteration, leading to a reduction in liquid saturation and an increase in gas saturation. Wu and Firoozabadi [15] found that a cationic fluoropolymer could be applied to change the sandstone wettability to neutral gas-wetting, and the adsorption of the fluorochemicals showed less impact on the gas permeability. The liquid saturation of fluids trapped in porous media could be reduced by more than $25 \%$ after gas-wetting alteration under high-temperature and -pressure conditions [16]. Meanwhile, liquid mobility and gas deliverability in a gas-liquid rock system can be enhanced by fluorochemical polymers without core damage, and sand production can also be relieved due to gas-wetting alteration [17]. Subsequently, a novel fluorine-containing acrylate copolymer was synthesized through emulsion polymerization, the imbibition volume and rate of liquids in the rock decreased sharply following gas-wetting alteration, helping to mitigate the water-blockage effect [18]. Sheydaeemehr et al. [19] simulated the effect of gas-wetting alteration on gas production and relative permeability in a Middle East oilfield, and the results indicated that both gas and condensate production could be effectively improved following gas-wetting alteration, and the production plateau of the gas-condensate reservoir could be extended. In China, gas-wetting alteration has been conducted in the central and northwest oilfields, and the results show that the relative permeabilities of gas and liquid were substantially enhanced by gas-wetting alteration [20]. It is worth noting that the desorption of fluorochemicals also influences the permanence of gas-wetting alteration, which is neglected in the current studies.

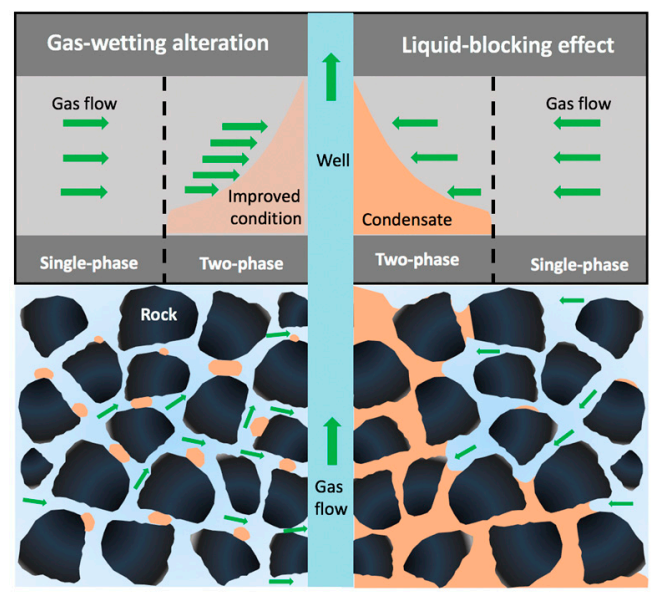

Figure 2. Sketch of mitigation of liquid-blocking effect by gas-wetting alteration in gas condensate reservoir.

In summary, both fluorosurfactants and fluoropolymers can be used to eliminate the liquid-blocking effect by improving liquid mobility, and the carbon-fluorine bond on the molecule plays a vital role in achieving gas-wetting alteration. The relevance between surface wettability and the fluorine content of the fluorochemical molecules has been investigated by experiments and molecular simulation, finding that the fluorine amount of fluorosurfactant molecule is proportional to its hydrophobicity [21]. 
Additionally, the surface morphology of a solid is also closely associated to its surface wettability, with high surface roughness being one of the prerequisites for fabricating a super gas-wetting surface.

\subsection{Wettability Alteration}

Wettability is the phenomenon whereby a fluid tends to replace another fluid on a solid surface, and is determined by the balance between adhesive and cohesive forces [22]. For conventional oil reservoirs, rock wettability can be characterized as water-wet, oil-wet, mixed-wet, and intermediate-wet according to the predominance of fluids on the rock surface [23]. Rock can be considered to be liquid-wetting (water-wet or oil-wet) if the liquid can spread on the rock surface, or the contact angles of liquids are lower than $90^{\circ}$; the rock can be regarded to be intermediate-wet if the contact angle of liquid droplet is close to $90^{\circ}$. Additionally, a reservoir might be both water-wet and oil-wet because of the complex structure of the pore throat, and can be denoted as being mixed-wet. Wettability alteration refers to the process of transition between liquid-wetting (water-wet, oil-wet) and intermediate-wet through the use of surfactants or polymers in a liquid-liquid-rock system. Generally, oil recovery can be enhanced following wettability alteration; the rock will spontaneously imbibe water, which will displace out due to the increase in affinity to the water phase, and then the capillary force for the oil phase will transfer from a resistance force into a displacing force under these circumstances [24]. However, conventional surfactants or polymers can only achieve intermediate-wet, and further enhancement of oil/gas recovery through wettability alteration is limited.

Gas-wetting refers to a solid surface with high surface free energy being replaced by a surface with low free energy that has a better affinity for air, but on which it is difficult for water and oil phases to spread, indicating that the contact angles of both water and oil are more than $90^{\circ}$. Gas-wetting alteration through fluorochemicals involves gas-liquid-rock systems, while wettability alteration only occurs in liquid-liquid-rock systems, which is the major difference between gas-wetting alteration and wettability alteration. The Wenzel and Cassie-Baxter models are the classic theories that have been used to describe the wetting regime of liquids on solid surfaces [25], but they are unable to reflect the wetting regime of gas-wetting. Meanwhile, previous studies have shown that the flow in a liquid-wetting reservoir obviously differs from that in gas-wetting reservoirs [12,26-29]; our understanding of the flow behavior of fluids in gas-wetting porous media is still limited. The performance of wettability alteration depends on multiple factors, such as the usage and types of chemicals and reservoir conditions. The performance of gas-wetting alteration is mainly influenced by the fluorine content of the gas-wetting agents, the surface morphology of gas-wetting adsorption, and the reservoir conditions. Considerable work needs to be accomplished in order to better understand the relationship between gas-wetting alteration and wettability alteration.

\subsection{Gas-Wetting Measurement}

This section discusses the methods for gas-wetting evaluation, including the static contact angle method, the OWRK method, the spontaneous imbibition test, the capillary rise test, the nuclear magnetic resonance technique, and streaming potential measurement. Additionally, the improvements and deficiencies of the current techniques are also described.

\subsubsection{Static Contact Angle Measurement}

Static contact angle measurement (CA) is one of the principal methods used to quantitatively evaluate rock wettability, and it has the advantages of high accuracy and easy operation [30]. The mechanism of contact angle measurement is to quantify the static contact angles of the liquid phases in an air-liquid-rock system. A gas-condensate reservoir can be regarded as a $\mathrm{CH}_{4}$-liquid-rock system, while the mobile phases in a conventional reservoir are only composed of water and oil phases; hence, the major limitation of the current method is its inability to be conducted in $\mathrm{CH}_{4}$-liquid-rock systems. In a $\mathrm{CH}_{4}$-liquid-rock system, rock can be considered to be liquid-wetting (water-wet or oil-wet) if the liquids spread on the rock surface or the contact angles of the liquid droplets are lower 
than $90^{\circ}$; the rock can be regarded as intermediate gas-wetting if the contact angles of the liquid droplets are close to $90^{\circ}$; the rock can be considered to be gas-wetting if the contact angles of the liquid droplets are within the range $90 \sim 120^{\circ}$; and if the contact angles of water and oil phases are more than $120^{\circ}$, and at least one exceeds $150^{\circ}$, the rock wettability can be recognized to be superhydrophobic or superoleophobic, namely, to be super gas-wetting [31-33]. it is worth noting that static contact angle measurement has limitations under the following circumstances: (1) the measurement error is non-negligible when the contact angle of the liquid droplet is below $20^{\circ}$; (2) the droplet size and the roughness of the solid surface will have an impact on the accuracy. However, the foregoing limitations can be offset by controlling the liquid amount and standardizing the surface treatment of the sample; therefore, static contact angle measurement can still be a reliable and convenient method used to evaluate the rock wettability.

Recently, Tabar et al. proposed a novel contact angle measurement based on the axisymmetric drop shape analysis, and found that there exists a correlation between contact angle, droplet volume, and surface roughness [34]. Moncayo-Riascos et al. [21] used the molecular dynamics model to predict the contact angle of water droplets after gas-wetting alteration, finding that the simulation results matched the measured contact angle well. In consideration of the non-ideality of the solid surface, contact angle hysteresis (CAH) is also a vital parameter for characterizing the wetting state of the solid surface; the smaller the contact angle hysteresis, the weaker the drop adhesion [35,36]. Generally, the definition of a super gas-wetting surface is that the advancing contact angle is larger than $150^{\circ}$ and the contact angle hysteresis is less than $10^{\circ}[37,38]$.

\subsubsection{Owens-Wendt-Rabel-Kaelble Method}

The surface free energy (SFE) is derived from the intermolecular interactions after the generation of the new surface, and is a key factor that can be used to predict the wettability regime of a solid surface [39]. Typically, the Owens-Wendt-Rabel-Kaelble (OWRK) method, the Wu method, and the Van Oss-Chaudhury-Good method are employed to quantitatively estimate the change in the free energy of the solid surface before and after wettability alteration [40-42]. The surface free energy consists of polar force and dispersion force, which can be calculated using Young's equation based on the contact angles of liquids with varying polarities on the solid surface. The surface free energy can be calculated using the OWRK method, as described in Equation (1) [42]. The polar (dispersion) force is used to describe the interaction between polar (non-polar) substances and the solid surface, the rock will exhibit different affinities for liquids with varying polarities. The contact angles of both water and oil on a gas-wetting surface are obviously higher than those on a liquid-wetting surface, leading to a major difference in surface free energy. Therefore, the surface free energy can be an effective parameter for reflecting the gas-wetting regime of rock surfaces. Additionally, Gindl et al. compared the methods used to calculate the surface free energy of solid surfaces, including the Zisman method, Berthelot's approximation, the Fowkes method, and the acid-based approach [43]. However, these methods involve more than two liquids, and the calculation results depend heavily on the choice of the liquids. Neumann proposed an "equation of state" theory to determine the solid surface free energy by introducing an empirical constant to the mentioned methods, the calculation results are reasonable, but one major limitation of this method is that only the total surface free energy can be estimated [44,45].

$$
\gamma_{s l}=\gamma_{s v}+\gamma_{l v}-2\left(\sqrt{\gamma_{s v}^{D} \gamma_{l v}^{D}}+\sqrt{\gamma_{s v}^{P} \gamma_{l v}^{P}}\right)
$$

where $\gamma_{s l}$ is the interfacial free energy between the liquid and solid, $\gamma_{s v}^{D}$ and $\gamma_{l v}^{D}$ denote the dispersive part, while $\gamma_{s v}^{P}$ and $\gamma_{l v}^{P}$ represent polar part of solid surface energy and liquid surface energy, respectively.

\subsubsection{Spontaneous Imbibition Test}

Spontaneous imbibition refers to the process of absorption in which a wetting fluid can spontaneously be imbibes into the pore throat due to capillary force. As early as 1950, Brownscombe and 
Dyes [46] realized the importance of spontaneous imbibition in oil recovery during the waterflooding process of water-wet fractured reservoirs. If the reservoir wettability is water-wet, then an oil-saturated rock will preferentially imbibe water into porous media, displacing the oil out as the rock is immersed in water [47]. However, for gas-condensate reservoirs, the imbibition of water or oil would cause serious formation damage to gas deliverability. The measurement of the spontaneous imbibition rate and the volume of the liquid phase by rock could be a reliable and reproducible method for the quantitative evaluation of gas-wetting. The principle behind the imbibition test is that a wetting phase tends to be spontaneously imbibed into a pore throat occupied by a nonwetting fluid. However, the method also raises the problem of measuring the imbibition volume of a liquid in the core sample with non-negligible errors [48]. Li and Firoozabadi suggested an improved imbibition apparatus by which the average liquid saturation in the sealed rock sample could be calculated [12]. Later on, an improved imbibition test in a $\mathrm{CH}_{4}$-liquid-solid system was suggested to simulate the imbibition process in gas-condensate reservoir conditions [32].

\subsubsection{Capillary Rise Test}

The capillary rise test has been studied for several decades, since its first proposal [49]. Compared with contact angle measurement, the capillary rise test has been extensively applied to evaluate the wetting regime of solid particles or powders [50]. Liquid is spontaneously imbibed into untreated capillaries due to capillary force, and then the affinity of the capillary tube towards a certain liquid can be evaluated by a liquid-level according to the Washburn equation [32,50]. The Washburn equation is shown in Equation (2) [51]. The capillary force will be the resistance force for liquids where the rock wettability is gas wetting. Therefore, the capillary can be considered to be gas-wetting when the liquid level in the capillary tube is negative; a theoretical contact angle can be calculated based on the different liquid levels. Obne premise need to first be satisfied before performing this method: total wetting liquid must be used to adjust the geometric factor. However, in practice, it is hard to find an ideal liquid that can totally wet any tube. Moreover, it is noteworthy that the surface physicochemical properties and sizes of tube also have a direct influence on the liquid level in the tube $[50,52,53]$.

$$
h^{2}=\frac{r \gamma_{l v} \cos \theta}{2 \eta} t
$$

where $h$ is the liquid level in capillary; $r, \gamma_{l v}$, and $\eta$ denote the capillary radius, surface tenson of liquid, and the viscosity of liquid, respectively; $t$ represents the imbibition time.

\subsubsection{Nuclear Magnetic Resonance Technique}

Understanding the wetting regime of a rock under reservoir conditions is crucial for choosing optimal development programs. Being different from the above-mentioned methods of wettability measurements, the nuclear magnetic resonance technique (NMR) has the advantage of monitoring the wettability change during the displacement process in situ; it is cost-effective and does not intervene in fluid saturation [54,55]. The principle of this method is to measure the transverse relaxation time of the wetting phase (for example, the water phase) used to reflect the pore size distribution of the water-wet rock; the wetting state of the rock can be determined once the change in the relaxation time of wetting phase has been detected. Currently, the NMR technique is only used to predict water-wet, oil-wet, or mixed-wet, although its application in gas-wetting evaluation can be expected. Moreover, there are other classic methods, such as the Amott test and the USBM index, that are time-consuming, expensive, and are unable to monitor the wettability change in real time.

\subsubsection{Streaming Potential Measurement}

Streaming potential method (SPM) can be employed to investigate the wetting state of the intact rock sample since there is a close correlation between the surface wettability and the electrical charge of rock [56]. Streaming potential is derived from the charge transportation that occurs when a fluid 
flows through surface-charged porous media or under an external potential gradient, the excess charge within the double layer would transfer to the fluid, generating a streaming current. SPM is suitable for predicting the wetting regime of porous media by measuring the average value of the zeta potential during the dynamic coreflooding process [57]. Based on the sensitivity and accuracy of the SPM technique, the gas-wetting degree of porous media can be predicted by calculating the streaming potential ratio between liquid and gas.

\section{Properties of Fluorochemicals}

Fluorine is the most electronegative element in nature, ranked third-highest among all elements in first ionization energy [58]. The C-F bond is the strongest bond, and endows fluorochemicals with the features of high thermal stability, low adhesion, and strong chemical inertness [59]. Since the discovery of poly (tetrafluoroethylene) (PTFE) in the 1930s, fluorochemicals have been widely used in various applications, such as functional and protective coatings [60], optical and electronic devices [61], special sensors [62], and in biotechnology [63]. Its applications in oilfields show that gas-wetting alteration by fluorochemicals can be an effective approach for improving gas deliverability in unconventional reservoirs [9,30]. The molecule structures of conventional surfactants and polymers are more vulnerable and easier to disrupt under high-temperature $\left(120 \sim 150^{\circ} \mathrm{C}\right)$ and -pressure $(37 \sim 111 \mathrm{MPa})$ conditions. The pressure and temperature of gas-condensate reservoirs increase with depth, and this aggravates the liquid-blocking effect near the wellbore region [64]; fluorochemicals could exhibit excellent hydrophobicity and oleophobicity under harsh environmental conditions, such as ultra-high temperatures and pressures $[65,66]$, and therefore, great interest has been aroused by the use of fluorochemicals as a preferable candidate for improving gas deliverability.

\subsection{Fluorosurfactants}

Fluorosurfactants are fluorine-containing surfactants that consist of a polar hydrophilic head and a hydrophobic and oleophobic $\mathrm{C}-\mathrm{F}$ tail, which can achieve gas-wetting alteration and decrease interfacial tension under harsh reservoir conditions because of its strong C-F bond [67]. Fluorosurfactants can be categorized as non-ionic, anionic, and cationic types according to the charge on their polar ends. Given the reality of reservoir rock being negatively charged, non-ionic and anionic fluorosurfactants would be suitable for avoiding excess loss. In 2000, fluorosurfactants were firstly used as a gas-wetting alteration agent for eliminating the liquid-blocking effect in gas-condensate reservoirs; oil and gas recovery was significantly improved after treatment [12]. Fahimpour and Jamiolahmady [68] further investigated the effect of anionic and nonionic fluorosurfactants on gas productivity in a gas-condensate reservoir; their research showed that liquid mobility could be substantially improved after treatment with fluorosurfactants. Gas permeability tends to sharply decline after liquid-blockage, which can be ameliorated after treatment with fluorosurfactant; this can be attributed to the adsorption of fluorosurfactant molecules on the pore throat [16].

Compared with conventional surfactants, such as SDBS and CTAB, fluorosurfactants also possess a better capacity to decrease interfacial tension to an ultra-low level that would be favorable to the improvement of oil and gas production [69]. Kamal et al. [70] studied a non-ionic ethoxylated fluorosurfactant for EOR applications, finding that the fluorosurfactant was thermally stable under conditions of high salinity and high temperature. Foam flooding is a promising EOR technique due to its ability to overcome the problem of gravity segregation and viscous fingering, but the instability of foam under high temperature and pressure hinders its further application. Siddiqui et al. [71] investigated the effect of an amphoteric amine oxide-based fluorosurfactant on foam stability by core flooding experiments; the low interfacial tension of foam system induced by the fluorosurfactant promoted foam stability under high-pressure conditions.

Fluorosurfactant molecules tend to adsorb on a solid surface to form monolayer or multilayer adsorption, which could transfer the surface wettability of rock from liquid-wetting to gas-wetting. The adsorption of fluorosurfactants on reservoir rock is dominated by the chemical composition, 
charge, and functional groups of the rock; the functional groups and charge on the polar end of fluorosurfactant also affect the adsorption process. Generally, both physical adsorption and chemical adsorption occur on rock surface [72]. The physical adsorption process dominates during the initial stage, and fluorosurfactant molecules scatter on the rock surface when the concentration of fluorosurfactant is low. Monolayer adsorption occurs on the rock surface when the concentration reaches the critical micelle concentration, as shown in Figure 3b. With the increase of concentration, fluorosurfactants tend to form a compact multi-adsorption layer on the rock surface due to the electrostatic force and dispersion force, as shown in Figure 3c; however, the affinity between the first layer of fluorosurfactant and the rock becomes stronger with the increase of temperature and time, and fluorosurfactants can bond with the hydroxyl or carboxyl groups of rock surface to form new bonds [73]. Therefore, the adsorption of fluorosurfactants on the rock surface can be considered to be a combination of physical adsorption and chemical adsorption.

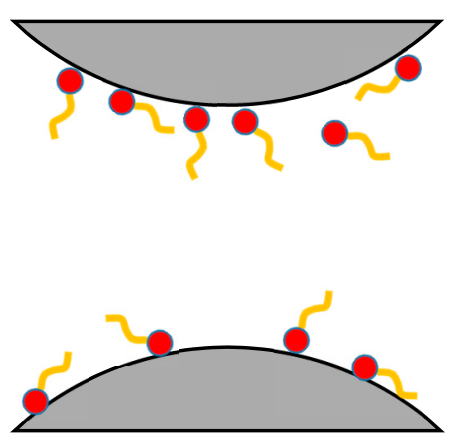

(a)

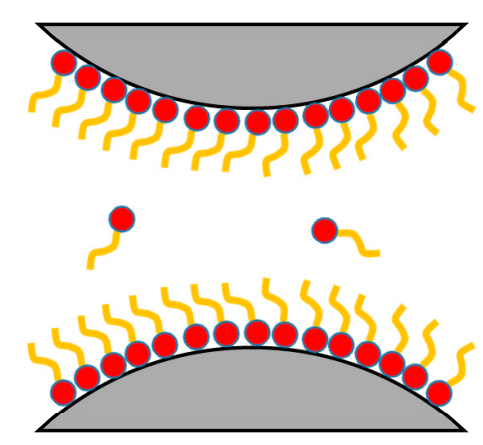

(b)

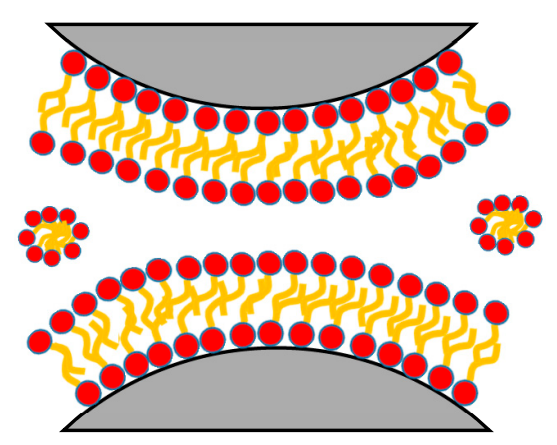

(c)

Figure 3. Schematic of fluorosurfactant adsorption on the rock surface: (a) low concentration; (b) critical micelle concentration; (c) high concentration. Reproduced with permission from [74], Copyright (C) 2002, American Chemical Society

\subsection{Fluoropolymers}

A fluoropolymer is defined as a polymer that consists of carbon and fluorine, which is composed of the C-C backbone and the C-F branches [75]. In 2000, Li and coauthors found that a fluoropolymer named "FC722" could be used to alter rock wettability to gas-wetting, which could effectively mitigate the liquid-blockage phenomenon during the development of gas-condensate reservoir [12]. Subsequently, some commercial fluoropolymer products, such as Zonyl 8740, G06, and Lot 201, were proved to have the capacity to alter the reservoir wettability from water-wet or oil-wet to intermediate gas-wetting, and the flow efficiency of gas could be further promoted after treatment $[15,76]$. However, the low solubility and high cost of the fluoropolymer impede its large-scale application. To address the above problems, fluoropolymers with varying morphologies have been synthesized by emulsion polymerization, such as core-shell [77], acorn-shape [78], and Janus-shape [79], as shown in Figure 4. The distribution and content of fluorine groups in fluoropolymers can be tuned by adjusting the synthesis process and fluorine-containing monomer usage, which can improve the solubility and reduce the cost of the fluoropolymer. 


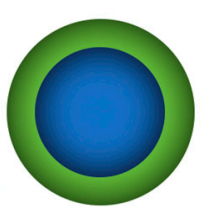

(a)

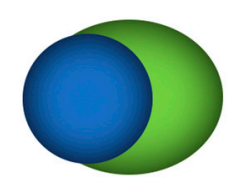

(d)

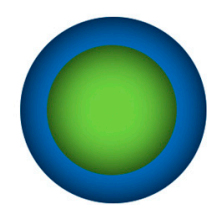

(b)

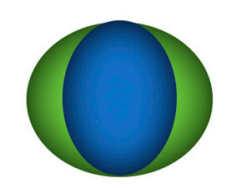

(e)

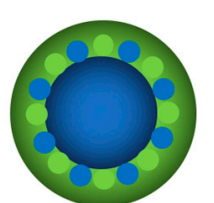

(c)

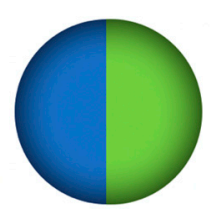

(f)

Core

Shell

Figure 4. Schematic of fluoropolymer particles: (a) core-shell structure; (b) inverted core-shell structure;

(c) triple-layer structure, the middle-layer contains a mixture of core monomer and shell monomer;

(d) acorn-shaped structure; (e) egg-shaped structure; and (f) Janus-shaped structure.

The fluoropolymer adsorption layer on a rock surface can not only modify the chemical composition of the rock, but can also change the surface microstructure of the rock $[80,81]$. In solution, fluoropolymers are normally dispersed as latex particles rather than single polymer chains, and the conformation of fluoropolymer depends on the nature of the monomer and the synthesis procedure. Once adsorbed on the rock surface, the arrangement of these latex particles can synergistically enhance gas-wetting degree by fabricating high surface roughness adsorption. The conformation of fluoropolymer could be dominated by the following elements: (1) the stretching of the hydrophobic group; (2) the repulsive interaction among the stretching groups; and (3) influential factors, for instance, temperature, $\mathrm{pH}$, and salinity [82].

\subsection{Fluorochemical-Modified Nanoparticles}

Recent advances in nanoparticle modification have attracted wide attention due to their tailored features and huge potential to enhance oil and gas recovery [83]. The primary applications of nanoparticles in the petroleum industry are related to alleviating formation damage and improving oil and gas recovery, such as the liquid-blocking effect, and aqueous phase trapping caused by hydraulic fracture [84]. Inspired by the unique microstructure of the lotus, nanomaterials with liquid-wetting can be decorated by fluorochemicals to prepare super gas-wetting nanoparticles that are of both high surface roughness and low surface free energy. Varying morphologies and chemical compositions of the adsorption layer can be obtained by adjusting the mass ratio between nanoparticles and fluorochemicals. Mousavi et al. [85] proposed a novel and effective approach for altering the wellbore wettability from liquid-wetting to intermediate gas-wetting using fluorochemical-modified nanoparticles, and found that the volume of liquid trapped in the pore throat and the pressure difference between the two sides of the core significantly decreased after gas-wetting alteration. Different morphologies of nanoparticles could also be decorated using fluorochemicals, such as nano-rod and peanut-shaped nanoparticles; gas-wetting degrees could be tuned by changing the morphologies of the nanoparticles [86-88]. Furthermore, varying sizes and kinds of nanomaterials could be modified by fluorochemicals to achieve different purposes, such as fluoropolymer-modified CNT for enhancing gas recovery [89], multi-scale nanoparticle blocking for EOR [90], and switchable superhydrophobic/superhydrophilic surfaces induced by UV light [91].

The surface modification of nanoparticles by fluorochemicals mainly includes chemical treatment, grafting of synthetic polymers, and the ligand exchange technique [92]. Among the above modification techniques, chemical treatment is a versatile and convenient method for improving the dispersibility and 
functionality of nanoparticles. Generally, the surface of the untreated nanoparticles covers numerous hydroxyl groups that could bond with the polar-end of fluorochemicals molecules to form gas-wetting nanoparticles, while the surface of the modified nanoparticle is covered with fluorochemical molecules. The mechanism for grafting fluorochemical on silica nanoparticles is presented in Figure 5, the spreading C-F bonds endow the modified nanoparticle with the features of hydrophobicity and oleophobicity.

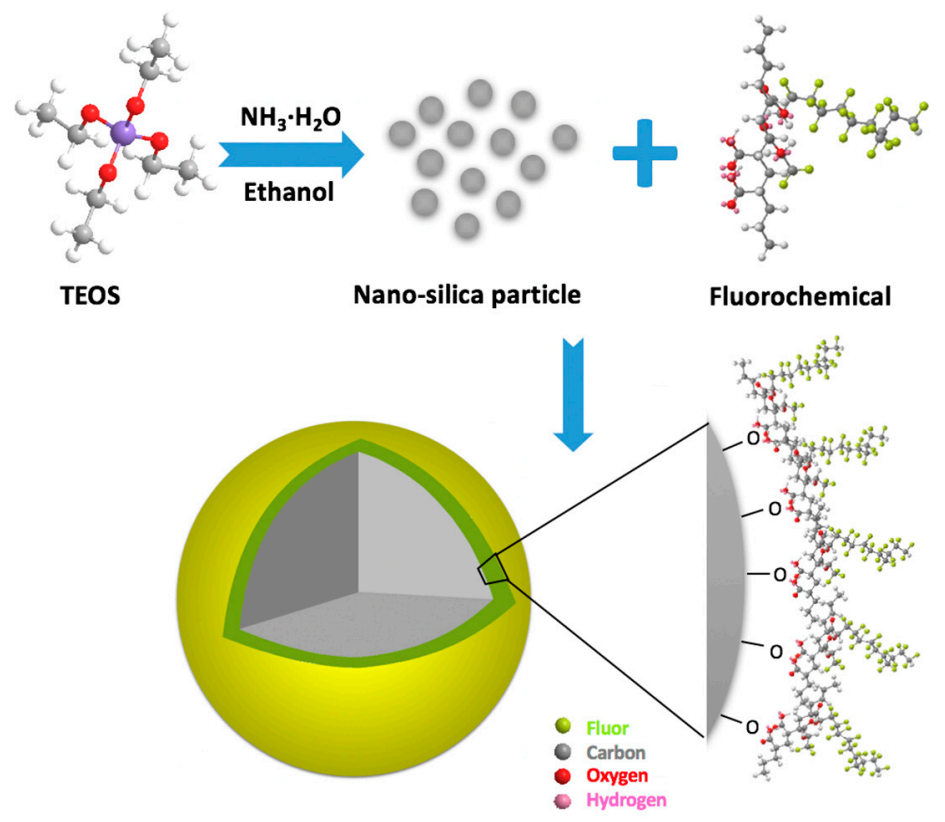

Figure 5. Sketch of the fabrication of nanoparticles with gas-wetting.

Various approaches can be used to investigate the modification mechanism of nanoparticles. The changes in adsorption peaks and newly formed bonds on fluorochemicals modified nanoparticle can be verified by FT-IR and XPS techniques. The morphologies of nanoparticles can be explored by Scanning Electron Microscopy (SEM), High-Resolution Transmission Electron Microscopy (HRTEM), and Confocal Laser Scanning Microscopy (CLSM). The Atomic Force Microscopy technique (AFM) could be employed to quantitatively estimate the roughness of the rock surface, and the relationship between surface roughness and wettability can also be obtained by the AFM technique.

\subsection{Morphologies of Fluorochemicals and Modified Nanomaterials}

The wettability of rock is closely related to its surface morphology and chemistry. Generally, there are two essential conditions required to achieve super gas-wetting: high surface roughness and low surface free energy. The morphologies of fluorochemicals vary according to their molecule conformations, which range from two-dimensional monolayers to three-dimensional multilayers. Hoseinpour et al. [93] altered the wettability of sandstone from water-wet to intermediate gas-wetting by coating a fluorocarbon surfactant film; the volume of spontaneous imbibition of water and decane significantly decreased after treatment. An obvious difference in the morphologies between fluorosurfactant and fluoropolymer can be observed, with the self-assembly of fluoropolymer latex particles on rock surface contributing to the decrease in surface free energy and increase in surface roughness [87] (Figure 6b). Furthermore, Jin et al. [94] studied the morphology of fluorosurfactant-modified nanoparticles, finding that the modified nanoparticles could adsorb on the rock surface by forming a gas-wetting adsorption layer, which contains numerous air cavities with huge capillary force, preventing liquids (water and oil) from entering the pore throats of the reservoir rock.

It has been found that the adsorption of fluorochemical-modified nanoparticles on rock surface matches the Freundlich model, indicating that the multilayer adsorption formed by modified 
nanoparticles might be involved in the chemisorption process, which can be verified by FT-IR and XPS techniques [23]. The morphology of rock surfaces treated by fluorosurfactant-modified nanoparticles can be investigated using the SEM and AFM techniques, as shown in Figure 6c,g. In addition to modifying spherical nanoparticles, one-dimensional nanomaterials, such as carbon nanotubes, can also be decorated. The adsorption layer formed by fluoropolymer-modified CNT is rich in air cavities, as shown in Figure 6d. According to the results of AFM analysis, it can be concluded that the surface roughness of solid surfaces increases with the size of the adsorbed substance, as shown in Figure 6e-h. For fluorochemicals, molecules with positive charge tend to self-assemble ahead of the air-solid-liquid interface on negatively charged rock surfaces due to the electrostatic force; then, the non-polar end with the characteristics of hydrophobicity and oleophobicity would be expose to air [95]. With respect to modified nanoparticles, they be adsorbed in multiple layers on the rock surface due to electrostatic force and chemical bonding; meanwhile, nanoparticles in self-assembled multilayers could impose structural disjoining pressure on the liquid-oil-rock boundary, facilitating the spread of nanofluid [96].
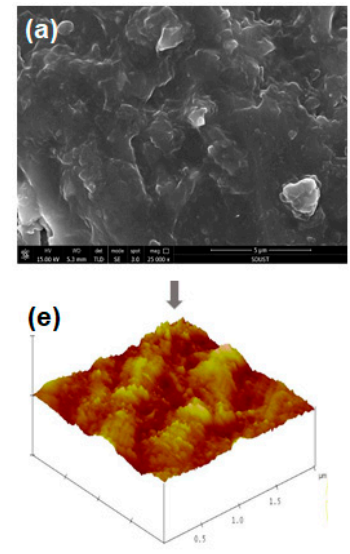

(i) I

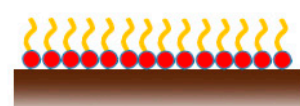

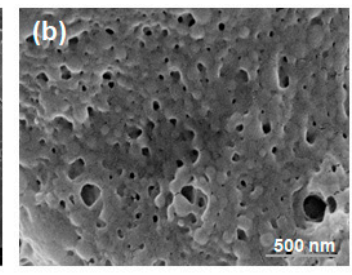

(f)

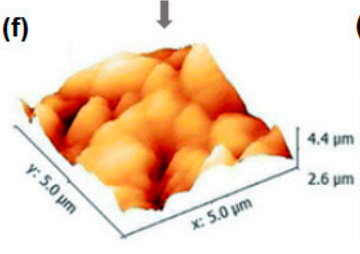

(j)

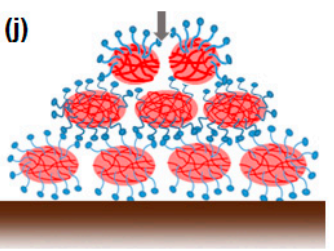

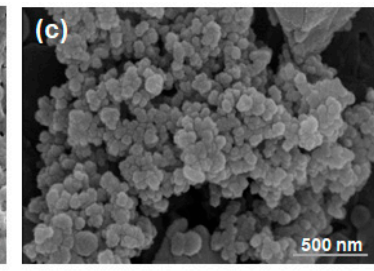

(g)

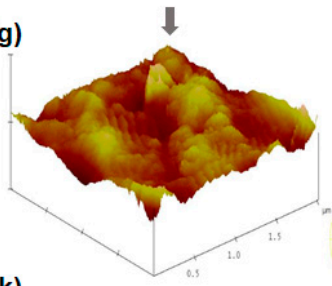

(k)

$\downarrow$

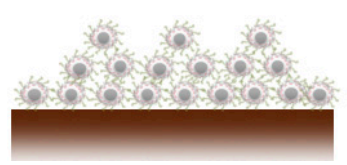

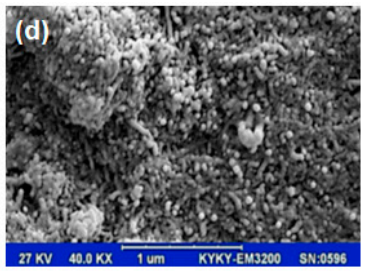

(h)
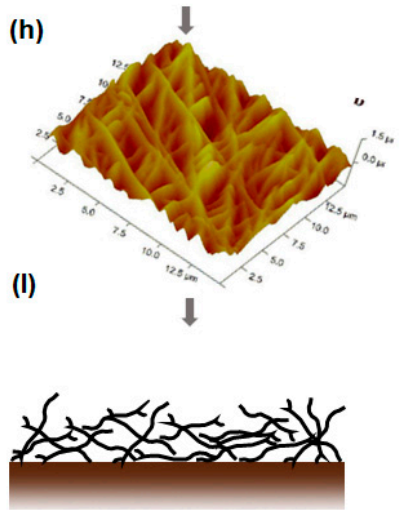

Figure 6. Morphology and adsorption of fluorochemicals with varying structures: (a) fluorosurfactant [32]; (b) fluoropolymer [87]; (c) fluorosurfactant-modified nanoparticle [94]; (d) fluoropolymer-modified CNT [89]; (e) AFM of fluorosurfactant [86]; (f) AFM of fluoropolymer [97], copyright (C) The Royal Society of Chemistry 2019; (g) AFM of fluorosurfactant-modified nanoparticle [86], Copyright (C) 2019, American Chemical Society; (h) AFM of fluoropolymer-modified CNT [98], Copyright (C) 2016, Springer Nature; (i-l) schematic of fluorochemicals and modified nanomaterials adsorption layer.

In summary, the greater the number of nano-sized cavities on the rock surface, the stronger the gas-wetting [99]. Despite the excellent gas-wetting of fluorochemicals, the fragile nature of the adsorption layer under external force hinders its large-scale application. Recently, a novel approach to strengthening the mechanical stability of superhydrophobic surfaces has been proposed by designing an inverted-pyramidal structure, which can resist high friction without reducing superhydrophobicity [100]. More work on fabricating super gas-wetting surfaces with different morphologies is encouraged to facilitate the application of new technology in petroleum engineering.

\section{Effects of Factors on Fluorochemicals}

The stability of fluorochemicals under harsh reservoir conditions is another major concern that can impact the stability of gas-wetting adsorption under complex conditions, such as high temperature, high pressure, high salinity, and long-term waterflooding [101]. 


\subsection{Temperature}

Complex and harsh environmental conditions in gas-condensate reservoirs, such as ultra-high temperature and high pressure, often degrade the fluid flow in porous media. Hence, it is pivotal for fluorochemicals to remain stable under high temperatures. In the 1960s, Johnson and Dettre [102] found that increasing the temperature could increase the hydrophobicity and oleophobicity of fluoropolymers (referred to as "temperature effects"), because the adsorption process of fluoropolymers on the solid surface can accelerate as the temperature changes. Esmaeilzadeh et al. [89] prepared a series of gas-wetting nanofluids to decrease the liquid accumulation and improve the gas deliverability, which are of permanent stability at a temperature of $160^{\circ} \mathrm{C}$; the contact angles of water and decane on sandstone samples treated with gas-wetting nanofluids slightly increase over time, as shown in Figure 7, and the velocity and amount of imbibition significantly decrease due to the change of capillary force. One potential reason for this could be that the molecule structures of fluorochemicals unfold as the temperature exceeds the evaporating temperature of crystal water [103], leading to the exposure of more C-F bonds on the rock surface. Currently, contact angle measurements are often conducted at room temperature without considering the impact of temperature and pressure, whereas the measurement under complex conditions could be able to reflect the actual wettability regime of reservoir rock. Recent research has confirmed that the contact angles of liquid on solid surfaces treated by fluorochemicals increase with the increase of both temperature and pressure; this phenomenon can be attributed to the enhancement of intermolecular interactions between gas and substrate under the conditions of high temperature and high pressure, leading to a weak liquid-wetting of the substrate [104].
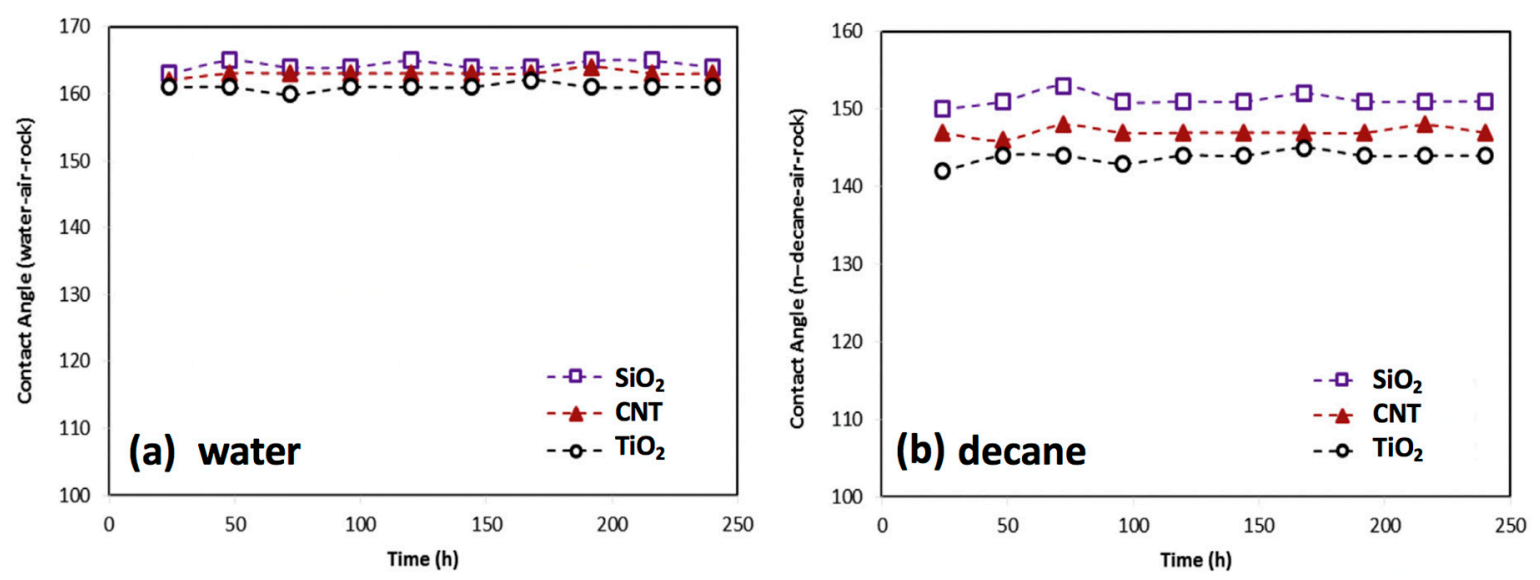

Figure 7. Impact of temperature on gas-wetting performance. Reprinted with permission from [89].

\section{2. $p H$}

$\mathrm{CO}_{2}$ injection into the depleted gas-condensate reservoir can improve the gas deliverability of the condensate reservoir [105]; however, an overdose of $\mathrm{CO}_{2}$ could cause the formation water to become weakly acidic. The $\mathrm{pH}$ of the formation water has a direct impact on rock wettability by changing the charge of rock surface, and $\mathrm{H}^{+}$or $\mathrm{OH}^{-}$could weaken the adsorption of fluorochemicals due to electrostatic repulsion, especially for these charged fluorosurfactants. Cationic fluorosurfactants tend to adsorb onto negatively charged surfaces, while positively charged surfaces attract fluorosurfactants with negative charge. Wu et al. [106] investigated the influence of $\mathrm{pH}$ value on a gas-wetting surface prepared by fluorosurfactant, finding that calcite with positive charge tends to bond with cationic fluorosurfactant if the $\mathrm{pH}$ value of the formation water is greater than 9. Karandish et al. [107] reported that the anionic fluorosurfactant Zonyl UR exhibited a better affinity to the solid surface when the $\mathrm{pH}$ value of the solution was approximately 2; rock wettability could be changed from strongly liquid-wetting to intermediate gas-wetting under acidic conditions. Jin et al. [87] explored the effect of $\mathrm{pH}$ value on the performance of fluoropolymers, and found that the rock surface could remain 
intermediate gas-wetting if the $\mathrm{pH}$ value of the solution was in the range of 5 to 7 , as shown in Figure 8 . Therefore, the adsorption of fluorochemicals on the rock surface would be tunable by adjusting the $\mathrm{pH}$ value of the solution, and the C-F bonds on fluorochemical would remain stable under the peracid or peralkaline condition.

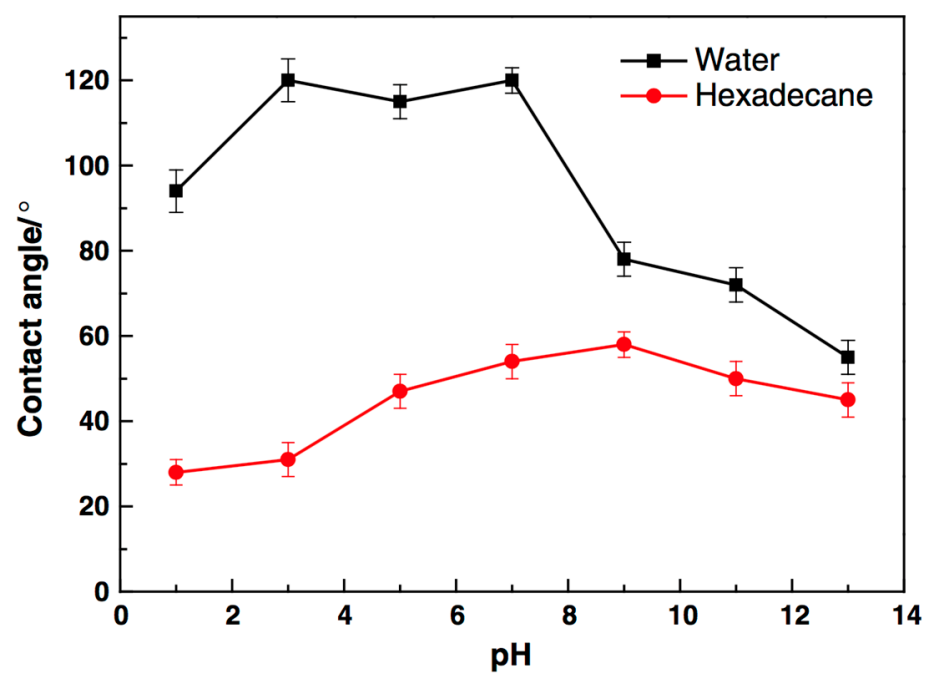

Figure 8. Impact of $\mathrm{pH}$ in the performance of fluoropolymer. Reproduced with permission from [87].

\subsection{Salinity}

Inorganic ions in aqueous condensate may derive from formation water and fracturing water, and high salinity of the gas-condensate reservoir often increases the difficulty of their development, such as through blockage induced by salt deposition, and destruction of fluorochemical stability by salt, resulting in colloidal coagulation. Tweheyo et al. [108] investigated the influence of salinity on the wettability of reservoir rock, and found that divalent inorganic ions, such as $\mathrm{Ca}^{2+}, \mathrm{Mg}^{2+}$, and $\mathrm{SO}_{4}{ }^{2-}$, had the potential to change rock wettability to water-wet at high temperature. However, the multivalent inorganic ions could impose compression of the electrical double layer (EDL) of fluorochemical molecules when exposed to formation water with high salinity. In a high-salinity solution, fluorochemical molecules tend to develop a coiled structure due to the electrostatic repulsion between the charged chain and inorganic cations, leading to a colloidal agglomeration [109]. Safaei et al. [110] investigated the effect of salinity on gas-wetting of the core surface, and found that the contact angles of water and oil decreased with increasing concentration of salts, and the mixture of salts had a more pronounced effect on the gas-wetting of the rock surface than did salt alone, as shown in Figure 9. Generally, multivalent inorganic cations $\left(\mathrm{Al}^{3+}, \mathrm{Fe}^{3+}\right)$ impose a more notable influence in the performance of fluorochemicals than low-valent inorganic cations [87], meaning that the gas-wetting of rock becomes weaker in a solution with a high concentration of multivalent inorganic cations. A possible reason for this phenomenon is that the ionic strengths of multivalent inorganic cations are distinctly higher than those of low-valent inorganic cations under equal concentration. Furthermore, there might exist competitive adsorption between inorganic ions and fluorochemical molecules on the rock surface [111]. The cations could adsorb on the negatively charged rock, and then form an electric double layer that is unfavorable for the adsorption of positively charged fluorochemicals. 

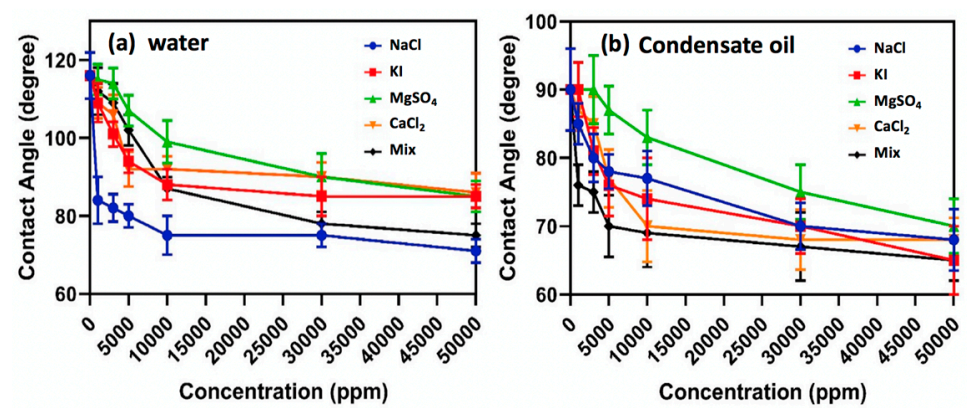

Figure 9. Impact of salinity on the performance of fluoropolymer. Reprinted with permission from [110], copyright (C) 2019 Elsevier B.V.

\subsection{Zeta Potential}

Most gas-condensate reservoirs are composed of carbonate, and the zeta potential of carbonate is also a vital parameter that determines gas deliverability. The potential determining ions, such as calcite and sulfate ions, can directly influence the water film thickness between condensate and rock by changing the surface charge of the carbonate rock, further affecting the rock wettability [111]. Xie et al. [112] investigated the effect of the expansion of the electric double layer on oil recovery, finding that wettability alteration could be induced by elevating the repulsive forces between water and rock interface. A recent study suggested that combinations of potential determining ions could be more pronounced in wettability alteration compared to ions alone, and sulfate ions are necessary for wettability alteration by calcite ions [113]. Saboori et al. [114] studied the effects of nanofluid potential on gas-wetting, and found that the liquid saturation decreased after treatment with nanofluids with high zeta potential. Ahmadi et al. [115] prepared gas-wetting $\mathrm{CaCO}_{3}$ nanoparticles, which were able to remediate the condensate blockage by gas-wetting alteration under positively charged conditions. Therefore, the zeta potentials of ions are closely associated with gas-wetting alteration, and the combination of potential determining ions and fluorochemicals could be a promising approach for mitigating the liquid-blockage.

\section{Effects of Fluorochemicals on Fluids in Porous Media}

Reservoir wettability is one of the vital factors that control the distribution and flow behavior of fluids in porous media [116]. The adsorption of fluorochemicals affects the fluid saturation in porous media, and then redistributes the fluid in the pore and throat. When considering a strongly gas-wetting system, gas functions as the wetting phase, and tends to occupy small pores with higher capillary forces, while the non-wetting phase (water or oil) would be distributed in the larger pores with lower capillary forces. This fluid distribution in porous media is most energetically favorable because it lowers the total energy of the system [116-118]. Consequently, the liquid-blocking effect can be relieved due to the improvement of the flow efficiency of water and oil.

\subsection{Effect on Liquid Saturation}

Fluid in the liquid-blocking region mainly consists of water and condensate, which could instantaneously be imbibed into the capillary and block the flow channels for gas. Fluorochemicals can reduce water saturation by promoting the flow efficiency of trapped water. However, it is a great challenge to accurately characterize the influence of wettability alteration on liquid saturation in pore throat. Freedman et al. [119] proposed an improved nuclear magnetic resonance method for measuring liquid saturation, by which the diffusion-free brine and oil distributions in saturated rocks can be accurately measured without causing damage to the core sample. A featured way of measuring the liquid saturation in a gas-wetting micro-model was suggested in [32], and the principle of this method is to calculate the pixel number of water and oil before and after gas-wetting alteration, respectively. This method has the advantages of high accuracy and continuous measurement compared with 
the previous methods, and could be a promising candidate for quantitively evaluating the effect of gas-wetting on liquid saturation.

\subsection{Effect on Flow Behavior in Porous Media}

\subsubsection{Detachment}

Detachment is a phenomenon in which the air-solid interface of liquid is replaced by a liquid-solid interface. The movement of a liquid droplet on a gas-wetting surface is different from that on a liquid-wetting surface, and the detachment of liquid droplets from surfaces with varying wettability is a critical point in improving flow efficiency. Zhu et al. [120] simulated the dynamic detachment of water droplets in a two-dimensional tube, and found that the pore structure and droplet volume were vital factors affecting the detachment efficiency of the water droplets. Jin and Wang [32] studied the detachment of water droplets on a super gas-wetting pore wall, and discovered that decreasing the resistance force of liquid on the rock surface was key to mitigating the liquid-blocking effect; the lower the resistance force, the greater the detachment efficiency of the liquid. Figure 10a shows the detachment of liquid droplets in a liquid-liquid-rock system; gas-wetting nanoparticles can impose a structural separation pressure over the junction of liquid-liquid-rock system, forcing the liquid phase to detach from the solid surface, leading to an increase in oil recovery. Figure 10b shows the distribution of fluid in liquid-wetting porous media. Figure 10c shows that the contact angle of a water droplet on a gas-wetting pore wall is about $125^{\circ}$; this droplet detaches easily under the interaction of displacing force compared with that on a liquid-wetting surface. It is worth noting that the detachment efficiency of the liquid droplet is proportional to the migration efficiency of gas in the liquid-blockage area. Figure 10d shows a sketch of a capillary rise test; the tube can be recognized as gas-wetting when the imbibition level of liquid in the tube is negative $(h<0)$. Then, the capillary force can be considered to be a displacing force for liquid, as can be observed in the lower part of Figure 10e. However, for liquid in a liquid-wetting tube, the capillary force acts as the resistance force when the liquid intends to move, as shown in the upper part of Figure 10e. Hence, the flow behavior of fluid in channels can be tuned through gas-wetting alteration by fluorochemicals [121]. Figure 10f represents the liquid levels in a gas-wetting capillary tube, a sharp reduction in liquid level can be observed after gas-wetting alteration, the calculated contact angles of water and oil are more than $90^{\circ}$.
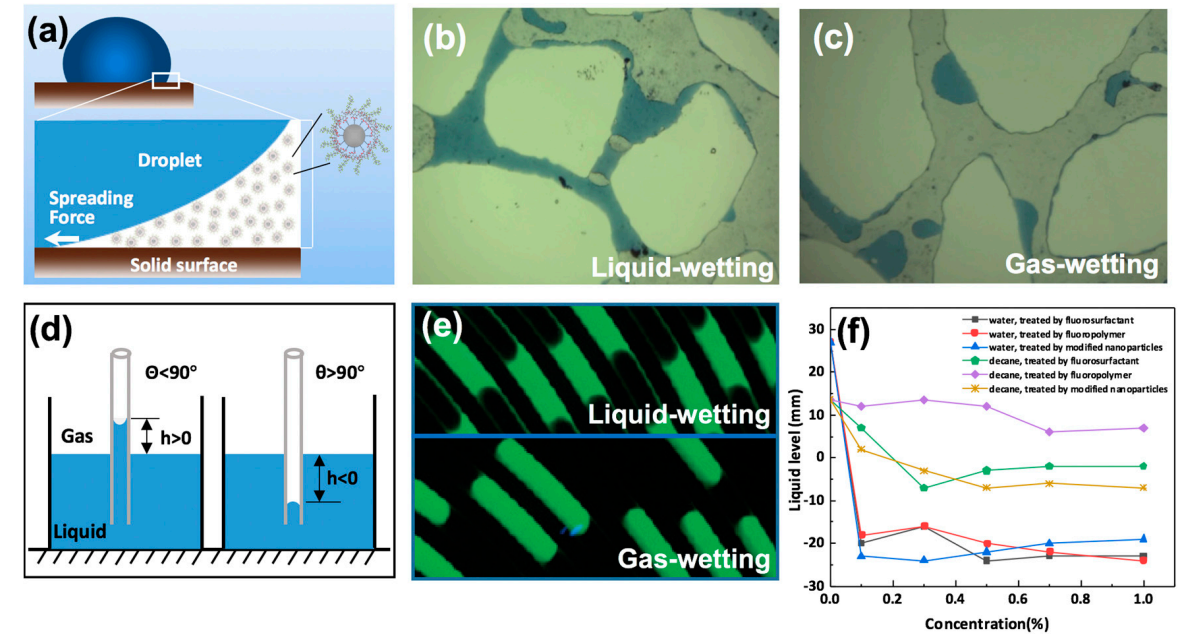

Figure 10. The movement of fluids in porous media and capillary: (a) detachment of liquid droplet in a liquid-liquid-solid system; (b) water in a pore throat with liquid-wetting; (c) water in a pore throat with gas-wetting (Reprinted with permission from [32]); (d) sketch of capillary rise test; (e) liquid in capillary before and after being treated with fluoropolymer, adapted with permission from [121], Copyright (C) 2011, American Chemical Society; (f) the liquid levels in a gas-wetting tube. Reproduced with permission from [94], Copyright (C) 2016 Elsevier. 


\subsubsection{The Transition of the Liquid Bridge}

The liquid bridge refers to the liquid trapped in a multiphase flow system where the neighboring pore throats can be connected by small volumes of encountered liquid, which can tremendously confine the gas flow in the wellbore region, leading to a sharp decline in gas production. Generally, the larger the contact surface between the droplet and the solid, the greater the viscous resistance required for its movement. Figure 11 demonstrates the transition of a liquid bridge in the pore throat; the liquid bridge can transform from a concave shape (large contact area) to a convex shape (small contact area) after gas-wetting alteration, and an obvious decline in liquid saturation can be observed as the liquid bridge transition occurs. Therefore, the capillary force in the pore throat switches from resistance force to displacing force after gas-wetting alteration, which can substantially accelerate the migration efficiency of the liquid bridge [122]. The efficient transition of the liquid bridge can effectively reduce the saturation of the discontinuous phase in the liquid-blocking region. Additionally, the pressure difference between the two sides of the liquid bridge also has an impact on the transition of the liquid bridge, which has a close relationship with the geometry, contact angle, and volume of the liquid bridge.

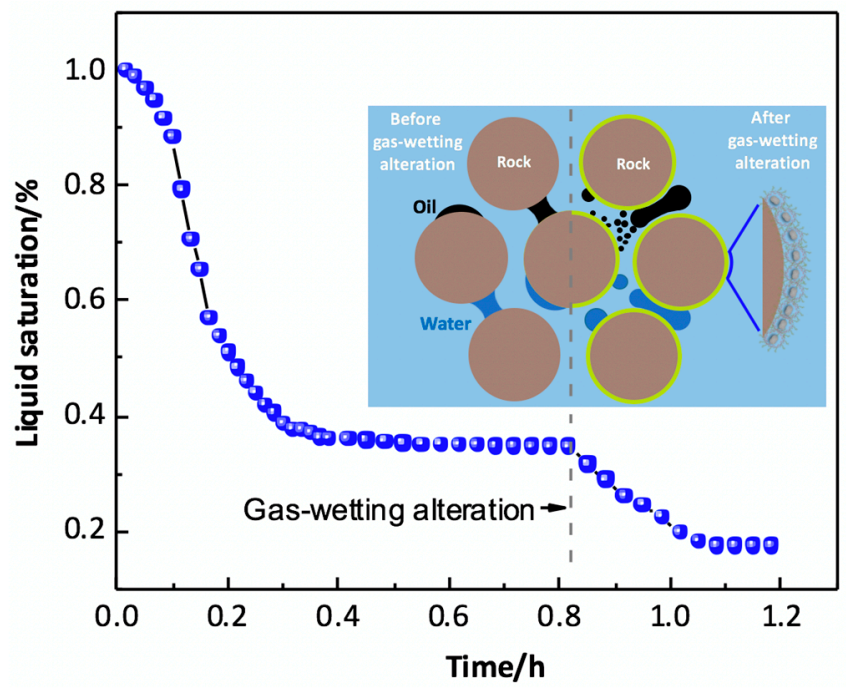

Figure 11. Liquid bridge transition in the pore throats with varying wettability. Adapted with permission from [86], Copyright (C) 2019, American Chemical Society.

\subsection{Gas-Wetting Model}

Both the Wenzel model and the Cassie-Baxter model are classical theories used to describe the wetting regime of a solid surface. However, the above models are subject to limitations when it comes to gas-wetting. The liquid phase can only wet the upside pillars on a solid surface, and cannot enter the bottom regions of the pillars, which are occupied by air due to the high capillary force. Therefore, the bottom regions remain non-wettable because of the existence of numerous cavities on the rock surface; hence, the wettability model for gas-wetting can be regarded as a complex of the Wenzel model and the Cassie-Baxter model, as shown in Figure 12a,b. It is worth noting that the movement of liquid on a gas-wetting surface is also different from that on a water-wet or oil-wet surface. Hao et al. [123] investigated the movement of liquid droplets on a superhydrophobic surface under airflow, and found that the advancing contact angle of the droplet continuously increased, and the wetting front of the liquid contacted the neighboring pillar during detachment. Given this reality, it is reasonable to conclude that the wetting regime of liquid droplets could continuously switch between the Wenzel regime and the Cassie-Baxter regime when they move on the gas-wetting surface under external force, as shown in Figure 12c. 


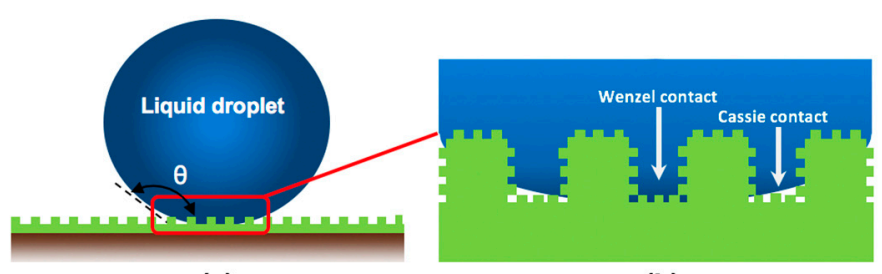

(a)

(b)

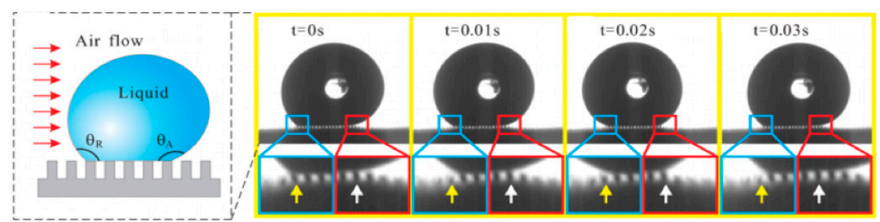

(c)

Figure 12. The movement of water on a solid gas-wetting surface: (a) the wetting regime of gas-wetting; (b) the gas-wetting model consists of the Wenzel model and the Cassie-Baxter model (reproduced with permission from [86], Copyright (C) 2019, American Chemical Society); (c) dynamic liquid on a solid surface with hydrophobicity. (Reproduced with permission from [123], Copyright (C) 2013, American Chemical Society).

\section{Outlook/Future}

Natural gas constitutes more than $25 \%$ of global energy demand, and a further increase can be predictable. Gas-condensate reservoirs exhibit complex couplings between multi-phase flow, interfacial behavior, and fluid distribution, and more proactive approaches are needed to bear the responsibility of improving gas deliverability. Fluorochemicals are well known for their excellent hydrophobicity and oleophobicity under harsh conditions, which can improve flow efficiency by gas-wetting alteration; surface modification of nanomaterials by fluorochemicals also is a versatile approach for enhancing the degree of gas-wetting. The morphologies of fluorochemicals and modified nanoparticles can be tuned to improve flow efficiency. There have been numerous studies focused on the synthesis and application of cost-effective fluorochemicals, and environmental protection with respect to fluorochemicals has also been one of the biggest concerns for the industry, since fluorine emissions during the petroleum refining process would devastate the ecosystem. Additionally, more accurate methods for evaluating the gas-wetting of rock under reservoir conditions are needed. Further research with respect to the flow mechanism in the pore throat after gas-wetting alteration by fluorochemicals can be anticipated.

\section{Summary}

This review provides an overview of gas-wetting alteration and the mechanism by which it improves flow efficiency. The conclusions can be drawn as follows:

(1) The liquid-blocking effect occurring during the development of the gas-condensate reservoir has aroused wide attention because of its severe damage; gas-wetting alteration by fluorochemicals could be regarded as a promising remediation approach;

(2) The methods for evaluating the gas-wetting of reservoir rock were summarized; the factors that affect gas-wetting were investigated;

(3) Varying sizes and kinds of nanomaterials can be modified by fluorochemicals, the mechanisms of fluorochemicals adsorption layer with varying surface morphologies were illustrated; the surfaces with more air cavities tend to exhibit stronger gas-wetting;

(4) The flow behavior of the fluids in a gas-wetting pore throat is distinctly different from that in a liquid-wetting pore throat. The wetting regime of the solid surface with gas-wetting might be a complex of the Wenzel regime and the Cassie-Baxter regime. 
Author Contributions: Conceptualization, J.S., J.J., T.A.H.N. and K.L.; methodology, J.J.; Data curation, J.J. and J.L.; Formal analysis, J.J. and J.S.; Investigation, K.R.; Methodology, R.W., Y.B. and X.H.; Project administration, K.L. and J.W.; Supervision, J.S. and K.L.; Writing-original draft, J.J. and T.A.H.N.; Writing—review \& editing, J.S. All authors have read and agreed to the published version of the manuscript.

Funding: National Natural Science Foundation of China (Major Program, 51991361), Program for Entrepreneurial and Innovative Leading Talents of Qingdao (18-1-2-15-zhc), the Fundamental Research Funds for the Central Universities (20CX06045A), the Joint Funds of the National Natural Science Foundation of China (U1762212), CNPC Science and Technology Project (2018A-3907), CNPC Science and Technology Project (Major Program, zd2019-183-005).

Acknowledgments: We gratefully acknowledge the support extended by the National Natural Science Foundation of China, CNPC Engineering Technology R\&D Company Limited, China University of Petroleum (East China), and the suggestions from anonymous reviewers.

Conflicts of Interest: The authors declare no conflict of interest.

\section{References}

1. Coskuner, G. Performance Prediction In Gas Condensate Reservoirs. J. Can. Pet. Technol. 1999, 38, 32-36. [CrossRef]

2. Yang, D.; Zhu, G.; Liu, J.; Su, J.; Zhang, B.; Fei, A. Distribution of global condensate gas field and major factors controlling its formation. Earth Sci. Front. 2010, 17, 339-349.

3. Vošta, M. Global changes and new trends within the territorial structure of the oil, gas and coal industries. Acta Oeconomica Pragensia 2009, 17, 45-59. [CrossRef]

4. Miller, N. Increasing Well Productivity in Gas Condensate Wells in Qatar's North Field. Master Thesis, Texas A \& M University, College Station, TX, USA, 2010.

5. Fan, L.; Harris, B.W.; Jamaluddin, A.J.; Kamath, J.; Mott, R.; Pope, G.A.; Shandrygin, A.; Whitson, C.H. Understanding gas-condensate reservoirs. Oilfield Rev. 2005, 10, 16-25.

6. Shi, C. Flow Behavior of Gas-Condensate Wells; Stanford University: Stanford, CA, USA, 2009.

7. Sayed, M.A.; Al-Muntasheri, G.A. Mitigation of the Effects of Condensate Banking: A Critical Review. SPE Prod. Oper. 2015, 13, 205-212. [CrossRef]

8. Alvarado, V.; Manrique, E. Enhanced oil recovery: An update review. Energies 2010, 3, 1529-1575. [CrossRef]

9. Ganie, K.; Idris, A.K.; Mohshim, D.F.; Wan Sulaiman, W.R.; Mohd Saaid, I.; Abdul Malik, A. A review on the wettability alteration mechanism in condensate banking removal. J. Pet. Sci. Eng. 2019, 183, 106431. [CrossRef]

10. Noh, M.H.; Firoozabadi, A. Wettability Alteration in Gas-Condensate Reservoirs to Mitigate Well Deliverability Loss by Water Blocking. SPE Reserv. Eval. Eng. 2008, 11, 676-685. [CrossRef]

11. Ahmed, T. Reservoir Engineering Handbook; Gulf Professional Publishing: Houston, TX, USA, 2018.

12. Li, K.; Abbas, F. Experimental Study of Wettability Alteration to Preferential Gas-Wetting in Porous Media and Its Effects. SPE Reserv. Eval. Eng. 2000, 3, 139-149.

13. Ganjdanesh, R.; Rezaveisi, M.; Pope, G.A.; Sepehrnoori, K. Treatment of Condensate and Water Blocks in Hydraulic-Fractured Shale-Gas/Condensate Reservoirs. SPE J. 2016, 21, 665-674. [CrossRef]

14. Li, K.; Firoozabadi, A. Phenomenological Modeling of Critical Condensate Saturation and Relative Permeabilities in Gas/Condensate Systems. SPE J. 2000, 5, 138-147. [CrossRef]

15. Wu, S.; Firoozabadi, A. Permanent Alteration of Porous Media Wettability from Liquid-Wetting to Intermediate Gas-Wetting. Transp. Porous Media 2010, 85, 189-213. [CrossRef]

16. Wang, Y.; Jin, J.; Ma, L.; Li, L.; Zhao, X. Influence of Wettability Alteration to Preferential Gas-Wetting on Displacement Efficiency at Elevated Temperatures. J. Dispers. Sci. Technol. 2015, 36, 1274-1281. [CrossRef]

17. Tang, G.Q.; Firoozabadi, A. Wettability Alteration to Intermediate Gas-Wetting in Porous Media at Elevated Temperatures. Transp. Porous Media 2003, 52, 185-211. [CrossRef]

18. Feng, C.; Kong, Y.; Jiang, G.; Yang, J.; Pu, C.; Zhang, Y. Wettability modification of rock cores by fluorinated copolymer emulsion for the enhancement of gas and oil recovery. Appl. Surf. Sci. 2012, 258, 7075-7081. [CrossRef]

19. Sheydaeemehr, M.; Sedaeesola, B.; Vatani, A. Gas-condensate production improvement using wettability alteration: A giant gas condensate field case study. J. Nat. Gas Sci. Eng. 2014, 21, 201-208. [CrossRef] 
20. Liu, Y.; Zheng, H.; Huang, G.; Li, G.; Li, K. Improving Production in Gas/Condensate Reservoirs by Wettability Alteration to Gas Wetness, In Proceedings of the SPE/DOE Symposium on Improved Oil Recovery, Tulsa, OK, USA, 22-26 April 2006; Society of Petroleum Engineers: Richardson, TX, USA, 2006.

21. Moncayo-Riascos, I.; Hoyos, B.A. Fluorocarbon versus hydrocarbon organosilicon surfactants for wettability alteration: A molecular dynamics approach. J. Ind. Eng. Chem. 2020, 88, 224-232. [CrossRef]

22. Cassie, A.; Baxter, S. Wettability of porous surfaces. Trans. Faraday Soc. 1944, 40, 546-551. [CrossRef]

23. Erfani Gahrooei, H.R.; Ghazanfari, M.H. Application of a water based nanofluid for wettability alteration of sandstone reservoir rocks to preferentially gas wetting condition. J. Mol. Liq. 2017, 232, 351-360. [CrossRef]

24. Alvarez, J.O.; Schechter, D.S.J.S.R.E. Engineering, Wettability alteration and spontaneous imbibition in unconventional liquid reservoirs by surfactant additives. SPE Reserv. Eval. Eng. 2017, 20, 107-117. [CrossRef]

25. Wang, B.; Zhang, Y.; Shi, L.; Li, J.; Guo, Z. Advances in the theory of superhydrophobic surfaces. J. Mater. Chem. 2012, 22, 20112-20127. [CrossRef]

26. Hazlett, R.; Chen, S.; Soll, W. Wettability and rate effects on immiscible displacement: Lattice Boltzmann simulation in microtomographic images of reservoir rocks. J. Pet. Sci. Eng. 1998, 20, 167-175. [CrossRef]

27. Morrow, N.R.; Xie, X. Oil recovery by spontaneous imbibition from weakly water-wet rocks. Petrophysics 2001, 42.

28. Standnes, D.C.; Nogaret, L.A.D.; Chen, H.-L.; Austad, T. An Evaluation of Spontaneous Imbibition of Water into Oil-Wet Carbonate Reservoir Cores Using a Nonionic and a Cationic Surfactant. Energy Fuels 2002, 16, 1557-1564. [CrossRef]

29. Anderson, W.G. Wettability Literature Survey-Part 6: The Effects of Wettability on Waterflooding. J. Pet. Technol. 1987, 39, 1605-1622. [CrossRef]

30. Anderson, W. Wettability literature survey-part 2: Wettability measurement. J. Pet. Technol. 1986, 38, 1246-1262. [CrossRef]

31. Butt, H.-J.; Semprebon, C.; Papadopoulos, P.; Vollmer, D.; Brinkmann, M.; Ciccotti, M. Design principles for superamphiphobic surfaces. Soft Matter 2013, 9, 418-428. [CrossRef]

32. Jin, J.; Wang, Y.; Nguyen, T.A.; Nguyen, A.V.; Wei, M.; Bai, B. The effect of gas-wetting nano-particle on the fluid flowing behavior in porous media. Fuel 2017, 196, 431-441. [CrossRef]

33. Wang, Y.; Gong, X. Superhydrophobic Coatings with Periodic Ring Structured Patterns for Self-Cleaning and Oil-Water Separation. Adv. Mater. Interfaces 2017, 4, 1700190. [CrossRef]

34. Azadi Tabar, M.; Ghazanfari, M.H.; Dehghan Monfared, A. On the size-dependent behavior of drop contact angle in wettability alteration of reservoir rocks to preferentially gas wetting using nanofluid. J. Pet. Sci. Eng. 2019, 178, 1143-1154. [CrossRef]

35. Yeh, K.-Y.; Chen, L.-J.; Chang, J.-Y. Contact Angle Hysteresis on Regular Pillar-like Hydrophobic Surfaces. Langmuir 2008, 24, 245-251. [CrossRef]

36. Marmur, A.; Della Volpe, C.; Siboni, S.; Amirfazli, A.; Drelich, J.W.J.S.I. Contact angles and wettability: Towards common and accurate terminology. Surf. Innov. 2017, 5, 3-8. [CrossRef]

37. Xia, F.; Jiang, L.J. Bio-inspired, smart, multiscale interfacial materials. Adv. Mater. 2008, 20, $2842-2858$. [CrossRef]

38. Yuan, Y.; Lee, T.R. Contact angle and wetting properties. In Surface Science Techniques; Springer: Berlin/Heidelberg, Germany, 2013; pp. 3-34.

39. Good, R.J. Surface free energy of solids and liquids: Thermodynamics, molecular forces, and structure. J. Colloid Interface Sci. 1977, 59, 398-419. [CrossRef]

40. Wu, S.; Brzozowski, K.J. Surface free energy and polarity of organic pigments. J. Colloid Interface Sci. 1971, 37, 686-690. [CrossRef]

41. Van Oss, C.J.; Chaudhury, M.K.; Good, R.J. Interfacial Lifshitz-van der Waals and polar interactions in macroscopic systems. Chem. Rev. 1988, 88, 927-941. [CrossRef]

42. Owens, D.K.; Wendt, R. Estimation of the surface free energy of polymers. J. Appl. Polym. Sci. 1969, 13, 1741-1747. [CrossRef]

43. Gindl, M.; Sinn, G.; Gindl, W.; Reiterer, A.; Tschegg, S. A comparison of different methods to calculate the surface free energy of wood using contact angle measurements. Colloids Surf. A: Physicochem. Eng. Asp. 2001, 181, 279-287. [CrossRef]

44. Neumann, A.; Good, R.; Hope, C.; Sejpal, M. An equation-of-state approach to determine surface tensions of low-energy solids from contact angles. J. Colloid Interface Sci. 1974, 49, 291-304. [CrossRef] 
45. Wang, S.; Zhang, Y.; Abidi, N.; Cabrales, L.J.L. Wettability and surface free energy of graphene films. Langmuir 2009, 25, 11078-11081. [CrossRef]

46. Brownscombe, E.; Dyes, A. Water-imbibition displacement-Can it release reluctant Spraberry oil. Oil Gas J. 1952, 50, 264-265.

47. Zhang, D.L.; Liu, S.; Puerto, M.; Miller, C.A.; Hirasaki, G.J. Engineering, Wettability alteration and spontaneous imbibition in oil-wet carbonate formations. J. Pet. Sci. Eng. 2006, 52, 213-226. [CrossRef]

48. Morrow, N.R.; Mason, G. Recovery of oil by spontaneous imbibition. Curr. Opin. Colloid Interface Sci. 2001, 6, 321-337. [CrossRef]

49. Washburn, E.W. The dynamics of capillary flow. Phys. Rev. 1921, 17, 273. [CrossRef]

50. Yang, B.; Chang, Q. Wettability studies of filter media using capillary rise test. Sep. Purif. Technol. 2008, 60, 335-340. [CrossRef]

51. Dullien, F.A.L.; Zarcone, C.; Macdonald, I.F.; Collins, A.; Bochard, R. The effects of surface roughness on the capillary pressure curves and the heights of capillary rise in glass bead packs. J. Colloid Interface Sci. 1989, 127, 362-372. [CrossRef]

52. Siebold, A.; Walliser, A.; Nardin, M.; Oppliger, M.; Schultz, J. Capillary rise for thermodynamic characterization of solid particle surface. J. Colloid Interface Sci. 1997, 186, 60-70. [CrossRef]

53. Galet, L.; Patry, S.; Dodds, J. Determination of the wettability of powders by the Washburn capillary rise method with bed preparation by a centrifugal packing technique. J. Colloid Interface Sci. 2010, 346, 470-475. [CrossRef]

54. Looyestijn, W.J.; Hofman, J. Engineering, Wettability-index determination by nuclear magnetic resonance. SPE Reserv. Eval. Eng. 2006, 9, 146-153. [CrossRef]

55. Liang, C.; Xiao, L.; Zhou, C.; Wang, H.; Hu, F.; Liao, G.; Jia, Z.; Liu, H. Wettability characterization of low-permeability reservoirs using nuclear magnetic resonance: An experimental study. J. Pet. Sci. Eng. 2019, 178, 121-132. [CrossRef]

56. Jackson, M.D.; Vinogradov, J. Impact of wettability on laboratory measurements of streaming potential in carbonates. Colloids Surf. A: Physicochem. Eng. Asp. 2012, 393, 86-95. [CrossRef]

57. Rahbar, M.; Pahlavanzadeh, H.; Ayatollahi, S.; Manteghian, M. Predicting the rock wettability changes using solutions with different $\mathrm{pH}$, through streaming potential measurement. J. Pet. Sci. Eng. 2018, 167, $20-27$. [CrossRef]

58. Fina, B.L.; Rigalli, A. The Chemistry of Fluorine. In Fluorine; Royal Society of Chemistry: London, UK, 2015; pp. 41-53.

59. Ameduri, B.; Boutevin, B. Well-Architectured Fluoropolymers: Synthesis, Properties and Applications; Elsevier: Amsterdam, The Netherlands, 2004.

60. Zielecka, M.; Bujnowska, E. Silicone-containing polymer matrices as protective coatings: Properties and applications. Prog. Org. Coat. 2006, 55, 160-167. [CrossRef]

61. Wang, J.L.; Chen, T.Y.; Chien, Y.H.; Su, G.D. Miniature optical autofocus camera by micromachined fluoropolymer deformable mirror. Opt. Express 2009, 17, 6268-6274. [CrossRef] [PubMed]

62. Graunke, T.; Schmitt, K.; Raible, S.; Wöllenstein, J. Towards Enhanced Gas Sensor Performance with Fluoropolymer Membranes. Sensors 2016, 16, 1605. [CrossRef] [PubMed]

63. Xu, W.; Hao, L.; An, Q.; Wang, X. Synthesis of fluorinated polyacrylate/polysilsesquioxane composite soap-free emulsion with partial trilayer core-shell structure and its hydrophobicity. J. Polym. Res. 2015, 22, 1-8. [CrossRef]

64. Speight, J.G. Gas condensate. In Natural Gas, 2nd ed.; Speight, J.G., Ed.; Gulf Professional Publishing: Boston, MA, USA, 2019; pp. 325-358.

65. Woodward, I.; Schofield, W.C.E.; Roucoules, V.; Badyal, J.P.S. Super-hydrophobic Surfaces Produced by Plasma Fluorination of Polybutadiene Films. Langmuir 2003, 19, 3432-3438. [CrossRef]

66. Anton, D. Surface-Fluorinated Coatings. Adv. Mater. 1998, 10, 1197-1205. [CrossRef]

67. Kovalchuk, N.M.; Trybala, A.; Starov, V.; Matar, O.; Ivanova, N. Fluoro- vs hydrocarbon surfactants: Why do they differ in wetting performance? Adv. Colloid Interface Sci. 2014, 210, 65-71. [CrossRef]

68. Fahimpour, J.; Jamiolahmady, M. Optimization of Fluorinated Wettability Modifiers for Gas/Condensate Carbonate Reservoirs. SPE J. 2015, 20, 729-742. [CrossRef] 
69. Jin, J.; Wang, H.; Jing, Y.; Liu, M.; Wang, D.; Li, Y.; Bao, M. An efficient and environmental-friendly dispersant based on the synergy of amphiphilic surfactants for oil spill remediation. Chemosphere 2019, 215, $241-247$. [CrossRef] [PubMed]

70. Kamal, M.S.; Sultan, A.S.; Al-Mubaiyedh, U.A.; Hussien, I.A.; Pabon, M. Evaluation of Rheological and Thermal Properties of a New Fluorocarbon Surfactant-Polymer System for EOR Applications in High-Temperature and High-Salinity Oil Reservoirs. J. Surfactants Deterg. 2014, 17, 985-993. [CrossRef]

71. Siddiqui, M.A.Q.; Gajbhiye, R.N.; Sultan, A.S.; Abu-Khamsin, S. Testing the Stability of Mixed $\mathrm{CO}_{2} / \mathrm{N}_{2}-\mathrm{Foam}$ Using New Fluorosurfactant for Enhanced Oil Recovery. In Proceedings of the SPE Kuwait Oil and Gas Show and Conference, Mishref, Kuwai, 11-14 October 2015; Society of Petroleum Engineers: Mishref, Kuwait, 2015; p. 9.

72. Nandwani, S.K.; Chakraborty, M.; Gupta, S. Adsorption of Surface Active Ionic Liquids on Different Rock Types under High Salinity Conditions. Sci. Rep. 2019, 9, 14760. [CrossRef] [PubMed]

73. You, L.; Zhang, W.; Kang, Y.; Chen, Z.; Liu, X. Stability of Fluorosurfactant Adsorption on Mineral Surface for Water Removal in Tight Gas Reservoirs. J. Chem. 2015, 2015, 980439. [CrossRef]

74. Rojas, O.J.; Macakova, L.; Blomberg, E.; Emmer, Å.; Claesson, P.M. Fluorosurfactant Self-Assembly at Solid/Liquid Interfaces. Langmuir 2002, 18, 8085-8095. [CrossRef]

75. McKeen, L.W. Chapter 11-Fluoropolymers. In Fatigue and Tribological Properties of Plastics and Elastomers, 2nd ed.; McKeen, L.W., Ed.; William Andrew Publishing: Oxford, UK, 2010; pp. 249-264.

76. Feng, C.; Kong, Y.; Jiang, G.; Yang, J.; Zhang, Y. Alteration of Porous Media Wettability to Gas-Wetting by Sol-Gel and Fluorochemical Surfactant. Pet. Sci. Technol. 2014, 32, 1898-1904. [CrossRef]

77. Marion, P.; Beinert, G.; Juhué, D.; Lang, J. Core-Shell Latex Particles Containing a Fluorinated Polymer in the Shell. 2. Internal Structure Studied by Fluorescence Nonradiative Energy Transfer. J. Appl. Polym. Sci. 1997, 64, 2409-2419. [CrossRef]

78. Misra, A.; Urban, M.W. Acorn-Shape Polymeric Nano-Colloids: Synthesis and Self-Assembled Films. Macromol. Rapid Commun. 2010, 31, 119. [CrossRef]

79. De Gennes, P.-G. Soft matter. Rev. Mod. Phys. 1992, 64, 645. [CrossRef]

80. Jiang, G. Gas Wettability of Reservoir Rock Surfaces with Porous Media; Gulf Professional Publishing: Houston, TX, USA, 2018.

81. He, L.; Nie, M.; Liang, G. Preparation and feasibility analysis of fluoropolymer to the sandstone protection. Prog. Org. Coat. 2008, 62, 206-213.

82. Feng, C.; Huang, X. Preparation and Self-assembly of Amphiphilic Fluoropolymers. In Fluorinated Polymers: Volume 1: Synthesis, Properties, Processing and Simulation; The Royal Society of Chemistry: London, UK, 2017; Volume 1, pp. 276-306.

83. Betancur, S.; Carrasco-Marín, F.; Franco, C.A.; Cortés, F.B. Development of Composite Materials Based on the Interaction between Nanoparticles and Surfactants for Application in Chemical Enhanced Oil Recovery. Ind. Eng. Chem. Res. 2018, 57, 12367-12377. [CrossRef]

84. Franco, C.A.; Zabala, R.; Cortés, F.B. Nanotechnology applied to the enhancement of oil and gas productivity and recovery of Colombian fields. J. Pet. Sci. Eng. 2017, 157, 39-55. [CrossRef]

85. Mousavi, M.A.; Hassanajili, S.; Rahimpour, M.R. Synthesis of fluorinated nano-silica and its application in wettability alteration near-wellbore region in gas condensate reservoirs. Appl. Surf. Sci. 2013, 273, 205-214. [CrossRef]

86. Jin, J.; Wang, Y.; Nguyen, T.A.; Bai, B.; Ding, W.; Bao, M. Morphology and surface chemistry of gas-wetting nanoparticles and their effect on the liquid menisci in porous media. Ind. Eng. Chem. Res. 2019, 58, 6747-6755. [CrossRef]

87. Jin, J.; Wang, Y.; Ren, J.; Nguyen, A.V.; Nguyen, T.A. The effect of fluoropolymer on wettability alteration of sandstone at elevated temperatures. J. Surfactants Deterg. 2016, 19, 1241-1250. [CrossRef]

88. Villegas, J.P.; Moncayo-Riascos, I.; Galeano-Caro, D.; Riazi, M.; Franco, C.A.; Cortés, F.B. Functionalization of $\gamma$-Alumina and Magnesia Nanoparticles with a Fluorocarbon Surfactant to Promote Ultra-Gas-Wet Surfaces: Experimental and Theoretical Approach. Acs Appl. Mater. Interfaces 2020, 12, 13510-13520. [CrossRef]

89. Esmaeilzadeh, P.; Sadeghi, M.T.; Fakhroueian, Z.; Bahramian, A.; Norouzbeigi, R. Wettability alteration of carbonate rocks from liquid-wetting to ultra gas-wetting using $\mathrm{TiO}_{2}, \mathrm{SiO}_{2}$ and $\mathrm{CNT}$ nanofluids containing fluorochemicals, for enhanced gas recovery. J. Nat. Gas Sci. Eng. 2015, 26, 1294-1305. [CrossRef] 
90. Yuan, B.; Wood, D.A. A comprehensive review of formation damage during enhanced oil recovery. J. Pet. Sci. Eng. 2018, 167, 287-299. [CrossRef]

91. Feng, X.; Zhai, J.; Jiang, L. The Fabrication and Switchable Superhydrophobicity of $\mathrm{TiO}_{2}$ Nanorod Films. Angew. Chem. Int. Ed. 2005, 44, 5115-5118. [CrossRef]

92. Kango, S.; Kalia, S.; Celli, A.; Njuguna, J.; Habibi, Y.; Kumar, R. Surface modification of inorganic nanoparticles for development of organic-inorganic nanocomposites-A review. Prog. Polym. Sci. 2013, 38, 1232-1261. [CrossRef]

93. Hoseinpour, S.-A.; Madhi, M.; Norouzi, H.; Soulgani, B.S.; Mohammadi, A.H. Condensate blockage alleviation around gas-condensate producing wells using wettability alteration. J. Nat. Gas Sci. Eng. 2019, 62, 214-223. [CrossRef]

94. Jin, J.; Wang, Y.; Wang, K.; Ren, J.; Bai, B.; Dai, C. The effect of fluorosurfactant-modified nano-silica on the gas-wetting alteration of sandstone in a $\mathrm{CH}_{4}$-liquid-core system. Fuel 2016, 178, 163-171. [CrossRef]

95. Kumar, N.; Varanasi, K.; Tilton, R.D.; Garoff, S.J.L. Surfactant self-assembly ahead of the contact line on a hydrophobic surface and its implications for wetting. Langmuir 2003, 19, 5366-5373. [CrossRef]

96. Nikolov, A.; Kondiparty, K.; Wasan, D.J.L. Nanoparticle self-structuring in a nanofluid film spreading on a solid surface. Langmuir 2010, 26, 7665-7670. [CrossRef]

97. Rao, Q.; Li, A.; Zhang, J.; Jiang, J.; Zhang, Q.; Zhan, X.; Chen, F. Multi-functional fluorinated ionic liquid infused slippery surfaces with dual-responsive wettability switching and self-repairing. J. Mater. Chem. A 2019, 7, 2172-2183. [CrossRef]

98. Kaur, N.; Kumar, V.; Dhakate, S.R. Synthesis and characterization of multiwalled CNT-PAN based composite carbon nanofibers via electrospinning. SpringerPlus 2016, 5, 483. [CrossRef] [PubMed]

99. Jin, J.; Liu, M.; Feng, L.; Wang, H.; Wang, Y.; Nguyen, T.A.; Wang, Y.; Lu, J.; Li, Y.; Bao, M. 3D Bombax-structured carbon nanotube sponge coupling with $\mathrm{Ag}_{3} \mathrm{PO}_{4}$ for tetracycline degradation under ultrasound and visible light irradiation. Sci. Total Environ. 2019, 695, 133694. [CrossRef]

100. Wang, D.; Sun, Q.; Hokkanen, M.J.; Zhang, C.; Lin, F.-Y.; Liu, Q.; Zhu, S.-P.; Zhou, T.; Chang, Q.; He, B.J.N. Design of robust superhydrophobic surfaces. Nature 2020, 582, 55-59. [CrossRef]

101. Wang, H.; Lu, H.; Zhang, X. Super-robust superamphiphobic surface with anti-icing property. RSC Adv. 2019, 9, 27702-27709. [CrossRef]

102. Johnson, R.E.; Dettre, R.H. The temperature dependence of wettability: Hexadecane on a fluoropolymer. J. Colloid Sci. 1965, 20, 173-176. [CrossRef]

103. Liu, Z.; Pan, C.; Lin, L.; Lai, H. Piezoelectric properties of PVDF/MWCNT nanofiber using near-field electrospinning. Sens. Actuators A: Phys. 2013, 193, 13-24. [CrossRef]

104. Sarmadivaleh, M.; Al-Yaseri, A.Z.; Iglauer, S. Influence of temperature and pressure on quartz-water-CO contact angle and $\mathrm{CO}_{2}$-water interfacial tension. J. Colloid Interface Sci. 2015, 441, 59-64. [CrossRef] [PubMed]

105. Barrufet, M.A.; Bacquet, A.; Falcone, G. Analysis of the Storage Capacity for $\mathrm{CO}_{2}$ Sequestration of a Depleted Gas Condensate Reservoir and a Saline Aquifer. J. Can. Pet. Technol. 2010, 49, 23-31. [CrossRef]

106. Wu, S.; Firoozabadi, A. Effect of salinity on wettability alteration to intermediate gas-wetting. SPE Reserv. Eval. Eng. 2010, 13, 228-245. [CrossRef]

107. Karandish, G.; Rahimpour, M.; Sharifzadeh, S.; Dadkhah, A. Wettability alteration in gas-condensate carbonate reservoir using anionic fluorinated treatment. Chem. Eng. Res. Des. 2015, 93, 554-564. [CrossRef]

108. Tweheyo, M.T.; Zhang, P.; Austad, T. The effects of temperature and potential determining ions present in seawater on oil recovery from fractured carbonates. In Proceedings of the SPE/DOE Symposium on Improved Oil Recovery, Tulsa, OK, USA, 22-26 April 2006; Society of Petroleum Engineers: Richardson, TX, USA, 2006.

109. Hiemenz, P.C.; Rajagopalan, R. Principles of Colloid and Surface Chemistry, Revised and Expanded; CRC Press: Boca Raton, FL, USA, 2016.

110. Safaei, A.; Esmaeilzadeh, F.; Sardarian, A.; Mousavi, S.M.; Wang, X. Experimental investigation of wettability alteration of carbonate gas-condensate reservoirs from oil-wetting to gas-wetting using $\mathrm{Fe}_{3} \mathrm{O}_{4}$ nanoparticles coated with Poly (vinyl alcohol), (PVA) or Hydroxyapatite (HAp). J. Pet. Sci. Eng. 2020, 184, 106530. [CrossRef]

111. Strand, S.; Høgnesen, E.J.; Austad, T. Wettability alteration of carbonates-Effects of potential determining ions $\left(\mathrm{Ca}^{2+}\right.$ and $\left.\mathrm{SO}_{4}{ }^{2-}\right)$ and temperature. Colloids Surf. A: Physicochem. Eng. Asp. 2006, 275, 1-10. [CrossRef] 
112. Xie, Q.; Liu, Y.; Wu, J.; Liu, Q. Ions tuning water flooding experiments and interpretation by thermodynamics of wettability. J. Pet. Sci. Eng. 2014, 124, 350-358. [CrossRef]

113. Boumedjane, M.; Karimi, M.; Al-Maamari, R.S.; Aoudia, M. Experimental investigation of the concomitant effect of potential determining ions $\mathrm{Mg}^{2+} / \mathrm{SO}_{4}{ }^{2-}$ and $\mathrm{Ca}^{2+} / \mathrm{SO}_{4}{ }^{2-}$ on the wettability alteration of oil-wet calcite surfaces. J. Pet. Sci. Eng. 2019, 179, 574-585. [CrossRef]

114. Saboori, R.; Azin, R.; Osfouri, S.; Sabbaghi, S.; Bahramian, A. Wettability alteration of carbonate rocks from strongly liquid-wetting to strongly gas-wetting by fluorine-doped silica coated by fluorosilane. J. Dispers. Sci. Technol. 2018, 39, 767-776. [CrossRef]

115. Ahmadi, R.; Farmani, Z.; Osfouri, S.; Azin, R. Condensate blockage remediation in a gas reservoir through wettability alteration using natural $\mathrm{CaCO}_{3}$ nanoparticles. Colloids Surf. A Physicochem. Eng. Asp. 2019, $579,123702$.

116. Anderson, W.G. Wettability Literature Survey Part 5: The Effects of Wettability on Relative Permeability. J. Pet. Technol. 1987, 39, 1453-1468. [CrossRef]

117. Burgess, I.B.; Mishchenko, L.; Hatton, B.D.; Kolle, M.; Lončar, M.; Aizenberg, J. Encoding complex wettability patterns in chemically functionalized 3D photonic crystals. J. Am. Chem. Soc. 2011, 133, 12430-12432.

118. Jiang, G.; Li, Y.; Zhang, M. Evaluation of gas wettability and its effects on fluid distribution and fluid flow in porous media. Pet. Sci. 2013, 10, 515-527.

119. Freedman, R.; Heaton, N.; Flaum, M.; Hirasaki, G.J.; Flaum, C.; Hürlimann, M. Wettability, Saturation, and Viscosity From NMR Measurements. SPE J. 2003, 8, 317-327.

120. Zhu, X.; Sui, P.C.; Djilali, N. Dynamic behaviour of liquid water emerging from a GDL pore into a PEMFC gas flow channel. J. Power Sources 2007, 172, 287-295. [CrossRef]

121. Kuhn, S.; Hartman, R.L.; Sultana, M.; Nagy, K.D.; Marre, S.; Jensen, K.F. Teflon-Coated Silicon Microreactors: Impact on Segmented Liquid- Liquid Multiphase Flows. Langmuir 2011, 27, 6519-6527. [PubMed]

122. Hu, X.; Hu, S. Microscopic Mechanism of Multiphase Fluids Flowing Through Rocks. In Physics of Petroleum Reservoirs; Springer: Berlin/Heidelberg, Germany, 2017; pp. 325-464.

123. Hao, P.; Lv, C.; Yao, Z. Droplet detachment by air flow for microstructured superhydrophobic surfaces. Langmuir 2013, 29, 5160-5166. [CrossRef]

(C) 2020 by the authors. Licensee MDPI, Basel, Switzerland. This article is an open access article distributed under the terms and conditions of the Creative Commons Attribution (CC BY) license (http://creativecommons.org/licenses/by/4.0/). 